\title{
LOS DAÑOS CORPORALES, ESTADO DEL ARTE DE LAS TENDENCIAS INDEMNIZATORIAS EN FRANCIA Y COLOMBIA
}

\author{
PERSONAL INJURIES, STATE \\ OF THE ART OF COMPENSATORY TENDENCIES \\ IN FRANCE AND COLOMBIA
}

\author{
FELIPE TABARES CORTÉS \\ DAVID RICARDO GÓMEZ RESTREPO**
}

Fecha de recepción: 7 de noviembre 2019

Fecha de aceptación 30 noviembre 2019

Disponible en línea: 30 de diciembre 2020

Para citar este artículo/To cite this article

Tabares Cortés, Felipe \& Gómez Restrepo, David Ricardo. Los daños corporales, estado del arte de las tendencias indemnizatorias en Francia y Colombia, 53 Rev.Ibero-Latinoam. Seguros, 275-314 (2020). https://doi.org/10.11144/Javeriana.ris53.dcea

doi:10.11144/Javeriana.ris53.dcea

\footnotetext{
* Abogado del CSJ de Colombia y de la barra de Francia (Paris), candidato a Doctor en Derecho Público, Université Sorbonne-Nouvelle, Maestría en Derecho de Seguros, Université Lyon III Jean Moulin, Centro de Formación de Abogados Université Paris II Panthéon-Assas, Academy on International Investment Disputes, Kuala Lumpur Regional Centre for Arbitration, Malasia, Especialista en Derecho Médico de la Universidad del Rosario, Contacto: felipetabarescortes@gmail.com

** Abogado egresado y Especialista en Responsabilidad Civil y Seguros de la Universidad EAFIT. Especialista en Seguros de la Pontificia Universidad Javeriana. Abogado de la dirección de procesos judiciales adscrita a la gerencia legal en seguros de Suramericana. Contacto: drgomez@sura.com.co
} 


\section{RESUMEN}

Los daños corporales han sido objeto recientemente de una amplia discusión jurídica, sin que ninguna iniciativa legislativa haya mediado en la organización de los sistemas de indemnización de este tipo de perjuicios. En Colombia, las Altas Cortes han instituido una clasificación propia que incluye subcategorías para cada tipo de perjuicio. En Francia, la nomenclatura Dintilhac unificó los criterios de indemnización, la cual se hizo efectiva a través de unos Acuerdos entre Aseguradores para la Indemnización de Perjuicios Corporales. En el presente artículo daremos cuenta de estas evoluciones en ambos países, de los conceptos transversales de la indemnización de los perjuicios corporales y de las perspectivas de evolución en la materia.

Palabras clave: Tipología de daños, daño corporal, seguros, acuerdos entre aseguradores, sistemas de indemnización, daños extrapatrimoniales.

\section{ABSTRACT}

Personal injuries have been the subject of extensive recent discussion without any legislative initiative having mediated in the organization of compensation systems for this type of damages. In Colombia, the High Courts have instituted their own classification that includes subcategories for each type of damages. In France, the Dintilhac nomenclature unified the criteria for compensation that is made effective through Agreements between Insurers. In this article, we will give an account of these developments in both countries, of the crosscutting concepts of compensation for bodily harms and of the prospects for the evolution on this matter.

Keywords: Typology of damages, bodily injuries, insurance, agreements between insurers, compensation systems, intangible losses. 


\section{SUMARIO}

Introducción - 1. Estado del arte de la indemnización de perjuicios corporales en Francia - 1.1. El sistema de evaluación de perjuicios o nomenclatura Dintilhac - 1.1.1. Circunstancias que motivaron la adopción de la nomenclatura Dintilhac-1.1.2. La nomenclatura única para la indemnización de los perjuicios corporales - 1.2. La adopción de la nomenclatura Dintilhac como único método de evaluación en el territorio de la República Francesa-1.2.1. Fuerza vinculante de la nomenclatura de perjuicios corporales en Francia - 1.2.2. El rol de los perjuicios corporales dentro del sistema jurídico de la responsabilidad civil 1.2.3. Aplicaciones prácticas de la nomenclatura Dintilhac - 1.2.3.1. Acuerdo entre los Aseguradores para la Indemnización de Perjuicios Corporales en el Ramo Automóviles - 1.2.3.2. La reparación de los perjuicios corporales luego de los atentados terroristas - 2. Estado del arte de la indemnización de perjuicios corporales en Colombia - 2.1. Presupuestos jurídicos de la reparación de los perjuicios corporales en Colombia - 2.1.1. Noción jurídica del perjuicio corporal en Colombia - 2.1.2. El Principio de Reparación Integral en el ordenamiento jurídico colombiano - 2.2. Concretización de la noción de los daños corporales en la reparación de víctimas - 2.2.1. Caracterización de las tipologías reconocidas por la Corte Suprema de Justicia y el Consejo de estado - 2.2.1.1. Los Perjuicios Inmateriales en la Jurisdicción Civil - 2.2.1.2. Los Perjuicios Inmateriales en la Jurisdicción Contencioso-Administrativa-2.2.2. Elementos jurídicos de la indemnización de perjuicios corporales a través de los contratos de seguro del mercado colombiano - 2.2.2.1. La noción de daños corporales en las pólizas de seguro del mercado colombiano-2.2.2.2. Acuerdos entre aseguradores del mercado colombiano y los perjuicios corporales - 3 . Conclusiones: la reparación de perjuicios corporales, miradas comparativas entre Colombia y Francia - Bibliografía. 


\section{INTRODUCCIÓN}

El daño corporal es uno de los temas esenciales del derecho de la responsabilidad civil y de seguros, que ha tenido evolución continua, particularmente en los últimos 50 años ${ }^{1}$. Esta área está estrechamente relacionada con la manera en que las personas consideramos, en una situación determinada, a nuestro semejante. Reconocer el dolor humano es tener empatía por las personas, tener la capacidad de identificarse con el otro y de compartir sus sentimientos. La empatía se convierte en un mandato jurídico cuando se configura a través del principio de solidaridad, el cual implica una adhesión a la causa del otro, una iniciativa de cooperación concretizada en un aporte monetario a la víctima para ayudarla a sobrellevar el dolor y solventar así las cargas económicas necesarias para lograr la recuperación e reincorporación a la normalidad social.

Si bien la reparación que se le debe a la víctima de un perjuicio corporal no es en sí misma una deuda monetaria, pues el dinero no podrá nunca restituir al estado anterior, dicho resarcimiento toma una forma monetaria cuya naturaleza no es in obligatione sino in solutione ${ }^{2}$. Es aquí cuando el derecho de la responsabilidad civil se encuentra con la realidad social y económica de la víctima luego de ocurrido el siniestro, momento en el cual la deuda de reparación se ve influenciada por un deber de solidaridad, e incluso de redistribución, que exige acompañar, en la mejor manera posible, las personas confrontadas a una situación de adversidad. La reparación de los perjuicios corporales es pues una de las manifestaciones más patentes del humanismo jurídico y representa el esfuerzo de la comunidad jurídica ${ }^{3}$ por limitar la brecha existente entre las declaraciones abstractas de derechos humanos y la realidad fáctica y permanente del estado de desigualdad entre las personas.

El daño corporal está definido como aquella afectación que sufre una persona en su integridad psicofísica ${ }^{4}$, que puede ser reparable desde el campo jurídico a través de una indemnización económica ${ }^{5}$. El derecho a la reparación de un daño corporal que tiene la víctima está fundamentado en las democracias contemporáneas, en la consagración constitucional del derecho a la vida, a la integridad física y a la dignidad humana, primigeniamente integrados en la Declaración de los Derechos del Hombre y del Ciudadano y la Declaración Universal de los Derechos del Hombre ${ }^{6}$.

\footnotetext{
1 M. Le Roy et al. (2018). L'évaluation du préjudice corporel, Ed: LexiNexis.

2 P. CAsson. Règles propres au dommage corporel, Dommages et intérêts: Évaluation judiciaire des dommages et intérêts, Jurisclasseur LexisNexis, Février 2017 (2019), recuperado: 13.10.2019.

3 Sobre la tradición jurídica humanista, ver M. Delmas-MarTy (2019). Sortir du pot au noir: l'humanisme juridique comme boussole, Paris: Buchet Chastel.

4 Una definición general del concepto de perjuicios extrapatrimoniales en: L. C. SÁnCHEZ HeRnÁNDEZ (2012). Reflexiones en torno a las funciones de la condena por daños extrapatrimoniales a la persona a partir del estudio de la "iniuria” del derecho romano clásico, Revista de Derecho Privado, Núm. 23 (2012): julio-diciembre.

5 Y. LamberT-Faivre et S. Porchy-Simon (2015). Droit du dommage corporel. Systèmes d'indemnisation, Ed: Précis Dalloz, ${ }^{\circ} 16$.

${ }^{6}$ A. LAUde et al. $(2015,2019)$. Existence d'un droit fondamental à la réparation du dommage corporel? n557-30, Le Lamy Droit de la santé, LamyLine, Wolters Kluwer.
} 
Los sistemas jurídicos occidentales privilegian la protección de víctimas ${ }^{7}$ e incluso establecen beneficios procedimentales ${ }^{8}$ y métodos especiales para garantizar la reparación ${ }^{9}$. Sin embargo, la multiplicidad de regímenes de indemnización, la heterogeneidad de métodos de evaluación, la falta de seguridad jurídica en temas de debate social y político álgido, la lentitud judicial y la pirámide de litigiosidad ${ }^{10}$, así como la insuficiente definición de los conceptos jurídicos de base, hacen que el objetivo de protección de víctimas no sea satisfecho ${ }^{11}$.

Para superar entonces esta "torre de Babel de definiciones del perjuicio corporal" 12 y "la lotería de los criterios de indemnización" 13 , una solución que sea adecuada y respetuosa de los principios de equidad y reparación integral, debe sistematizar las hipótesis fácticas relevantes bajo una identificación y calificación jurídica única y además del establecimiento de un monto máximo de indemnización que siga los criterios médicos y jurídicos repertoriados por los órganos estatales profesionales o académicos. Si Francia y Colombia tienen un amplio historial republicano y más de dos siglos de tradición casacionista, la situación económica y del aparato judicial es diferente, razón por la cual el análisis del tema de los perjuicios corporales exige realizar un recorrido que tome en cuenta dichas diferencias pero que también dé cuente de las similitudes. Así, nos proponemos presentar el estado del arte de la indemnización de perjuicios corporales en Francia (1), para luego mencionar cuál es el estado del arte de este tema en Colombia (2).

\section{ESTADO DEL ARTE DE LA INDEMNIZACIÓN DE PERJUICIOS CORPORALES EN FRANCIA}

Para abordar el tema de los perjuicios corporales en Francia es necesario mencionar el sistema de evaluación de perjuicios que se instituyó con la creación de la nomenclatura Dintilhac (1.1), para luego mencionar de qué manera dicho baremo se adoptó como único método de evaluación en el territorio francés (1.2).

\footnotetext{
7 Solarte Rodríguez, A. (2017). El principio favor victimae y su aplicación en el derecho colombiano, Anuario de Derecho Privado, 2017 Facultad de Derecho, pp. 257-304.

8 Ibidem.

9 En los países del orbe occidental existe variedad de fondos especiales de indemnización como una solución alternativa al método clásico de la responsabilidad civil, Taylor Simon. "L’indemnisation du risque thérapeutique en droit anglais et la possibilité d'un rapprochement des systèmes européens". In: Revue internationale de droit comparé. Vol. 57 N³,2005, pp. 717-732.

${ }^{10}$ Lalinde S. et al. (2010). Encuesta Nacional de Necesidades jurídicas, Dejusticia, Análisis general y comparativo para tres poblaciones.

11 P. Brun, et al. (2019). Dommage corporel: données de base théoriques et pratiques, $\mathrm{n}^{\circ} 224$, Le Lamy Droit de la responsabilité, Wolters Kluwer.

12 T. PAPART (2013). Regards croisés sur l'indemnisation du préjudice corporel en France et en Belgique, Revue Le Lamy Droit civil, No 106, Wolters Kluwer.

13 Rapágs. Busnelli F. Académie de droit européen de Trèves, Congrès 8 et 9 juin 2000, citado en Op. Cit. T. PAPART (2013).
} 


\subsection{El sistema de evaluación de perjuicios corporales $o$ "nomenclatura Dintilhac"}

Ciertos hechos motivaron e hicieron necesaria la implementación de un sistema de calificación y de liquidación de perjuicios (1.1.1), lo cual condujo al establecimiento de una nomenclatura única para la indemnización de víctimas de perjuicios corporales (1.1.2).

\subsubsection{Circunstancias que motivaron la adopción de la nomenclatura Dintilhac}

El tema de la liquidación de perjuicios corporales fue durante mucho tiempo objeto de una interpretación dejada al arbitrio judicial. Los jueces confrontaban las solicitudes que en este sentido hacían las víctimas a las compañías aseguradoras, y sobre todo seguían la valoración y liquidación que en este sentido realizaban los peritos y expertos.

Antes de 2004, en Francia se interpretaban de manera distinta las nociones de consolidación e indemnización de la incapacidad permanente parcial, puesto que se utilizaban indistintamente varios referentes. Existía además una multiplicidad de clasificaciones de perjuicios, según la jurisdicción y según la Corte de Apelaciones de que se tratara, sin que hubiera coherencia entre sí. Esta situación conducía a indemnizaciones muy diferentes según el juez que se tratara, lo que en ocasiones dejaba entrever una tendencia inflacionista de los magistrados y abogados ${ }^{14}$.

La disparidad en los criterios de indemnización creaba entonces cierta inseguridad jurídica y generaba unas reparaciones muy diferentes según la Corte que declaraba la responsabilidad. Por ello, no era extraño que algunos ciudadanos prefirieran incoar las reclamaciones indemnizatorias en la jurisdicción civil, que se mostraba más generosa que la jurisdicción administrativa en cuanto al monto de reparación de los perjuicios corporales ${ }^{15}$.

En algunos casos, fue una intención explícita del legislador y del gobierno el reconocer ciertos tipos de perjuicios según las coyunturas políticas momentáneas, o incluso con el objetivo de mejorar la suerte de algunos grupos específicos, a través de la creación de fondos especiales de indemnización". Es el caso de los judíos "pies-negros" de retorno en Francia luego de la guerra de Argelia; las víctimas de la contaminación luego de transfusiones sanguíneas ${ }^{17} \mathrm{o}$ más recientemente las víctimas de los ataques terroristas en París y en Niza del año 2015.

Pero además de ello, un caso en especial generó gran controversia respecto de la indemnización de perjuicios corporales. Se trató del caso Perruche, en el cual una persona nació con una severa incapacidad motora, luego de que su madre no fue diagnosticada a tiempo de rubéola. Buscando ser indemnizado por la culpa médica

\footnotetext{
14 M. Le Roy Et al. (2018). L'évaluation du préjudice corporel, Ed: LexiNexis.

15 S. Porchy-Simon, et al. (2015) Dommage corporel, Recueil Dalloz 2015, p. 2283.

16 C. Bloch (2018-2019). Domaine de l'indemnisation des victimes contaminées par le sida ou l'hépatite C à la suite d'une transfusion sanguine, Droit de la responsabilité et des contrats, Dalloz Action, Chapitre 6431.

17 P. Le Tourneau (2019). Droit des dommages corporels, Responsabilité: généralités, Dalloz Répertoire de droit civil.
} 
consistente en no haber diagnosticado a tiempo la enfermedad sufrida por la madre en gestación, la víctima solicitó a los jueces la declaración de responsabilidad médica. El asegurador del médico se opuso a tal acción puesto que, aunque la enfermedad hubiera sido diagnosticada a tiempo y la madre hubiera podido recurrir a una interrupción del embarazo, en el derecho francés no era posible obtener una indemnización por el hecho de haber nacido en estado de incapacidad permanente ${ }^{18}$.

Sin embargo, en el año 2001 la Corte Suprema Francesa (Cour de cassation), declaró que un niño discapacitado podía solicitar la indemnización que surge de su propio nacimiento en estado de incapacidad, ya que se trataba de una enfermedad gestacional cuya única solución hubiera sido el aborto oportuno ${ }^{19}$. Los gremios de aseguradores se opusieron férreamente a otorgar indemnizaciones en tales casos y anunciaron no desear continuar a asegurar esa especialidad médica, denunciando que esas jurisprudencias de la Corte de Casación ponían fuera de toda asegurabilidad el diagnóstico prenatal, además de que volvían prácticamente inasegurable toda la actividad de la ecografía obstétrica, en un ambiente que de por sí ya estaba influido por importantes alzas en las primas de los seguros de responsabilidad civil de los ginecobstetras ${ }^{20}$.

De esta forma, para evitar que una actividad social y económica de gran importancia como la especialidad obstétrica quedara desprovista de la protección ofrecida por los contratos de seguro, así como para responder a la oposición presentada por muchos sectores sociales y académicos, el legislador decidió adoptar una ley según la cual "nadie puede solicitar una indemnización que resulta de un daño consistente en el solo hecho de su propio nacimiento"21. Así, la ley impidió la indemnización del niño que nació con una incapacidad permanente en razón de un deficiente diagnóstico prenatal. Sin embargo, el perjuicio de los padres se declaró como legalmente indemnizable, a cargo de la solidaridad nacional, por la vía de la constitución de un Fondo Especial ${ }^{22}$.

El Consejo Constitucional declaró exequible la ley Anti-Perruche puesto que los médicos y las instituciones de salud que cometieron una culpa no están totalmente exentos de responsabilidad, ya que deben siempre responder respecto de los padres del niño discapacitado 23 .

La ley pasó posteriormente al análisis de la Corte Europea de Derechos Humanos de Estrasburgo que validó dicha norma, aunque las disposiciones transitorias consistentes en la aplicación retroactiva de la ley fueron sancionadas. El resultado fue que finalmente muchas víctimas de errores de diagnóstico prenatal pudieron solicitar

\footnotetext{
18 B. Edelman (2002). L'arrêt «Perruche»: une liberté pour la mort ?, Recueil Dalloz, p. 2349.

19 J. Landel (2019). Dommages corporels, Dictionnaire Permanent Assurances, Editions Législatives, ELNet.

20 P.L. Bras et al. (2007). Rapport de l'assurance de responsabilité médicale, Collège français d'échographie foetale.

21 Art. L11415 du Code de l'action sociale et des familles.

22 J. Penneau (2013, 2019). Préjudice, Répertoire de droit civil / Médecine: réparation des conséquences des risques sanitaires, Répertoire de droit civil 2013, Dalloz.

23 F. Limoge (2010) Des règles communes de gestion des dommages corporels, Argus de l'assurance, 2010, recuperado: https://www.argusdelassurance.com/le-poinT-sur/des-regles-communes-de-gestion-des-dommages-corporels.50808.
} 
indemnización por el solo hecho de su nacimiento en estado de invalidez ${ }^{24}$, aunque dicha protección no se convirtió en derecho vigente.

Este es un ejemplo de cómo el tema de los perjuicios corporales ha tenido un alto impacto social y político en Francia, al mismo tiempo que una incidencia muy importante para el mercado de seguros, teniendo en cuenta que para el año 2017 el costo total por siniestros corporales fue de 1 billón 188 millones de euros, correspondiendo a 32 millones de contratos de seguro ${ }^{25}$.

Así frente a una falta de claridad sobre las reglas aplicables, muchas voces dentro de la sociedad francesa manifestaron la urgencia de establecer una clasificación legislativa única de los perjuicios personales, de manera que se permitiera una indemnización por cada tipo de daño, identificando los montos que eran responsabilidad de cada aseguradora involucrada en la indemnización de las víctimas.

\subsubsection{La nomenclatura única para la indemnización de los perjuicios corporales}

En el año 2003 el Ministerio de Justicia ordenó la creación de una comisión de estudio sobre los perjuicios corporales liderado por la profesora Yvonne Lambert-Faivre, de la Universidad de Lyon, cutos resultados sirvieron de base al informe judicial que sobre la liquidación de estos perjuicios establecería posteriormente Jean-Pierre Dintilhac, presidente de la Segunda Sala Civil de la Corte de Casación ${ }^{26}$.

Este documento es actualmente el baremo utilizado para liquidación de perjuicios corporales en Francia. El rasgo principal de la nomenclatura Dintilhac, siguiendo en ello el trabajo de la profesora Lambert-Faivre, es que realizó una clasificación de perjuicios partiendo de la identificación y distinción de tres elementos principales. Primero, las víctimas directas y las víctimas indirectas; segundo, los perjuicios patrimoniales y los perjuicios extrapatrimoniales; y finalmente, los perjuicios anteriores y posteriores a la fecha de consolidación ${ }^{27}$.

Los perjuicios directos, sufridos por la víctima están divididos en los perjuicios patrimoniales y los perjuicios extrapatrimoniales. A su vez ambos están divididos en temporales y permanentes. Los perjuicios patrimoniales temporales son los gastos médicos actuales, la pérdida de ingresos profesionales y los gastos varios. Los perjuicios patrimoniales permanentes son la pérdida de ingresos profesionales futuros, la incidencia profesional y los gastos médicos futuros, la asistencia por una tercera

\footnotetext{
${ }^{24}$ La CEDH condamne la rétroactivité de la loi française "anti-Perruche" (2008) Le Monde, recuperado 13.09.2019: https:/www.lemonde.fr/societe/article/2005/10/06/la-cedh-condamne-la-retroactivite-de-laloi- francaise-anti-perruche_696611_3224.html.

25 Véase: Federación Francesa de Aseguradoras (2017). Les assurances en cas d'accidents corporels à adhésion individuelle, recuperado 13.09.2019 en: https://www.ffa-assurance.fr/etudes-eT-chiffres-cles/ les-assurances-en-cas-accidents-corporels-adhesion-individuelle-en-2017.

26 Y. LAMBerT-FAIVRe (2003). Rapport sur l'indemnisation du dommage corporel.

27 J. LANDel (2019). Dommages corporels, Dictionnaire Permanent Assurances, Editions Législatives, ELNet.
} 
persona, los gastos de adaptación de vivienda y de vehículo, y el perjuicio escolar, universitario o de formación.

Por su lado, los perjuicios extrapatrimoniales temporales son el déficit funcional temporal, el perjuicio de sufrimiento corporal y el perjuicio estético temporal. Los perjuicios extrapatrimoniales permanentes son el déficit funcional permanente, el perjuicio de ocio, el perjuicio estético permanente, el perjuicio sexual, el perjuicio de la perdida de perspectiva futura y los perjuicios permanentes excepcionales, reconocidos actualmente en caso de eventos terroristas. Esta clasificación puede identificarse en la tabla siguiente ${ }^{28}$ :

\begin{tabular}{|c|c|c|}
\hline \multicolumn{3}{|c|}{ Perjuicios directos (sufridos por la víctima) } \\
\hline & Perjuicios Patrimoniales & Perjuicios Extrapatrimoniales \\
\hline $\begin{array}{l}\text { Perjuicios } \\
\text { temporales }\end{array}$ & $\begin{array}{l}\text { Gastos médicos actuales (DSA) } \\
\text { Pérdida actual de ingresos profe- } \\
\text { sionales (PGPA) } \\
\text { Gastos Varios (FD) }\end{array}$ & $\begin{array}{l}\text { Déficit funcional temporal (DFT) } \\
\text { Sufrimiento corporal (SE) } \\
\text { Perjuicio estético temporal (PET) }\end{array}$ \\
\hline $\begin{array}{l}\text { Perjuicios } \\
\text { permanentes }\end{array}$ & $\begin{array}{l}\text { Pérdida ingresos profesionales } \\
\text { futuros (PGPF) } \\
\text { Incidencia profesional (IP) } \\
\text { Gastos médicos futuros (DSF) } \\
\text { Asistencia por una tercera persona } \\
\text { (ATP) } \\
\text { Gasto de adaptación de la vivienda } \\
\text { (FLA) } \\
\text { Gasto de adaptación del vehículo } \\
\text { (FVA) } \\
\text { Perjuicio escolar, universitario o de } \\
\text { formación (PSU) }\end{array}$ & $\begin{array}{l}\text { Déficit funcional permanente (DFP) } \\
\text { Perjuicio de ocio (PA) } \\
\text { Perjuicio estético permanente } \\
\text { (PEP) } \\
\text { Perjuicio sexual (PS) } \\
\text { Perjuicio de pérdida de la pers- } \\
\text { pectiva futura (PE) } \\
\text { Perjuicios Permanentes Excep- } \\
\text { cionales (PPE) }\end{array}$ \\
\hline
\end{tabular}

De otra parte, tenemos los perjuicios indirectos, sufridos por los próximos de la víctima, que pueden ser patrimoniales y extrapatrimoniales, dividiéndose a su vez en los perjuicios ocasionados por el deceso de la víctima directa o los que se ocasionan a pesar de la supervivencia de la víctima directa. De esta forma, los perjuicios patrimoniales indirectos, en caso de deceso de la víctima son los gastos de exequias, la pérdida de ingresos y los gastos diversos. Los perjuicios patrimoniales indirectos en caso de supervivencia de la víctima directa son la pérdida de ingresos y los gastos varios.

Los perjuicios extrapatrimoniales indirectos, en el caso del deceso de la víctima son la pérdida de compañía y el perjuicio de tristeza por la pérdida. Los perjuicios extrapatrimoniales indirectos, causados a pesar de la supervivencia de la víctima directa son el

${ }^{28}$ Traducción de tabla tomada de: Dossier. (2017). L'indemnisation du préjudice corporel. Annuaire Juridique Pénal, Dalloz. 
perjuicio de tristeza por la pérdida y los perjuicios extrapatrimoniales excepcionales. Esta clasificación está resumida en la siguiente tabla ${ }^{29}$ :

\begin{tabular}{|l|l|l|}
\hline \multicolumn{3}{|c|}{ Perjuicios indirectos (sufridos por los próximos de la víctima) } \\
\hline & \multicolumn{1}{|c|}{ Perjuicios Patrimoniales } & Perjuicios extrapatrimoniales \\
\hline $\begin{array}{l}\text { En caso de deceso de } \\
\text { la víctima directa }\end{array}$ & $\begin{array}{l}\text { Gastos de exequias (FO) } \\
\text { Pérdida de ingresos (PR) } \\
\text { Gastos diversos (FD) }\end{array}$ & $\begin{array}{l}\text { Pérdida de compañía (PAC) } \\
\text { Perjuicio de tristeza (PAF) }\end{array}$ \\
\hline $\begin{array}{l}\text { En caso de supervi- } \\
\text { vencia de la víctima } \\
\text { directa }\end{array}$ & $\begin{array}{l}\text { Pérdida de ingresos (PR) } \\
\text { Gastos varios (FD) }\end{array}$ & $\begin{array}{l}\text { Perjuicio de tristeza (PAF) } \\
\text { Perjuicios extrapatrimoniales } \\
\text { excepcionales (PEX) }\end{array}$ \\
\hline
\end{tabular}

Más recientemente, las Cortes de Apelaciones crearon un referencial de liquidación de perjuicios corporales ${ }^{30}$, basado en la nomenclatura Dintilhac que facilita la liquidación de perjuicios. Se trata de un repertorio de todas las sentencias que liquidan el monto de indemnización que precisa el valor de reparación otorgado a las víctimas, según las circunstancias particulares de cada caso. Este documento está constituido de un número importante de precedentes jurisprudenciales, y es accesible para todos los jueces y las aseguradoras ${ }^{31}$.

La nomenclatura Dintilhac uniformizó la manera de indemnizar a las víctimas y favoreció con ello la seguridad jurídica, la transparencia y efectividad de los recobros realizados entre las aseguradoras. En la práctica, una primera calificación es realizada por el médico que atiende a la víctima, principalmente siguiendo el documento "Misión de Peritajes Médicos Legales" 32 . En efecto, luego de la adopción de la nomenclatura Dintilhac, el gremio médico de expertos en perjuicios corporales adoptó en el año 2009 un instructivo referencial de los perjuicios corporales, a aplicar por los médicos en el momento de realizar la primera calificación de la situación de la víctima.

Finalmente, el cuerpo médico que sigue el tratamiento de la víctima está llamado a señalar una fecha de consolidación. La consolidación está definida como el momento en el cual las lesiones se configuran definitiva y permanentemente, de manera que seguir con el tratamiento no puede impedir la agravación del paciente. A partir de la consolidación puede apreciarse la existencia eventual de una afectación permanente a la integridad física y psíquica del paciente. Antes de la consolidación la víctima no recibirá sino prestaciones económicas provisionales. La consolidación es además el

\footnotetext{
${ }^{29}$ Traducción de tabla tomada de: Dossier. (2017). L'indemnisation du préjudice corporel. Annuaire Juridique Pénal, Dalloz.

${ }^{30}$ Référentiel indicatif de l'indemnisation du préjudice corporel des cours d'appel, Conférence des premiers présidents de cours d'appel de France, Septembre 2016.

31 Ecole nationale de la Magistrature (2016). Référentiel indicatif de l'indemnisation du préjudice corporel des cours d'appel.

${ }^{32}$ Association pour l'étude de la Réparation du Dommage Corporel (2014). Mission droit commun d'expertises médicales.
} 
momento a partir del cual se cuenta el término que tienen las aseguradoras para formular una oferta de indemnización a la víctima ${ }^{33}$.

Luego de la adopción de esta tipología la práctica judicial se ha configurado de manera que el rol de los abogados es adaptar los hechos a cada tipología del perjuicio, mientras que el papel de los jueces es controlar la calificación que se le da al supuesto fáctico de los casos sometidos a su jurisdicción. Cierto número de casos son objeto de un recurso de casación o incluso del procedimiento constitucional de la QPC, en los cuales se solicita aumentar o disminuir la noción de uno u otro de los perjuicios incluidos en la nomenclatura Dintilhac. La Cour de cassation guarda entonces competencia como Tribunal de Cierre.

\subsection{La adopción de la nomenclatura Dintilhac como único método de evaluación en el territorio de la República Francesa}

La uniformización del régimen de indemnización de perjuicios corporales tuvo un proceso particular de implementación puesto que no fue producto de una modificación introducida por vía legislativa (1.2.1). Ello no impidió que el derecho pretoriano le haya atribuido a este sistema un rol específico dentro de la dogmática del derecho de la responsabilidad civil (1.2.2). La nomenclatura Dintilhac tiene unas aplicaciones prácticas que deben ser mencionadas (1.2.3).

\subsubsection{Fuerza vinculante de la nomenclatura de perjuicios corporales en Francia}

Anteriormente se consideraba que el juez estaba legitimado a estimar la existencia de un daño por el solo hecho de haber verificado su existencia durante el proceso, sin que tuviera que demostrar cuáles fueron los elementos que le sirvieron para determinar el monto de la indemnización que ordenó ${ }^{34}$. La Corte de Casación había así otorgado a los jueces la autoridad de apreciar los diferentes tipos de perjuicios sufridos en los casos de daños corporales, además del método de indemnización que estimara como el más adecuado ${ }^{35}$.

Sin embargo, en lo que respecta a los daños corporales, desde la adopción de la nomenclatura Dintilhac en 2005, la tendencia es a su integración uniforme en todo el territorio de la República Francesa ${ }^{36}$. La nomenclatura Dintilhac es un documento técnico cuyo promotor, como se explicó más arriba, fue el Ministerio de Justicia luego

\footnotetext{
33 Op. cit. J. LANDEL (2019).

34 Cour de cassation, deuxième chambre, 18 avr. 1969, no 67-14.072, Bull. civ. II, no 82.

35 H. Adida-Canac (2011) Le contrôle de la nomenclature Dintilhac par la Cour de cassation, Recueil Dalloz pág. 1497.

${ }^{36}$ El territorio de la Republica incluye las entidades territoriales constituidas por las islas francesas ubicadas en todos los continentes. Esta presencia global, aunque reducida, ha permitido un eminente desarrollo de la normatividad en seguros y responsabilidad civil, así como en el derecho internacional y constitucional.
} 
de la discusión social que generaron ciertos temas cuyo impacto económico era muy alto. Es un documento que no tiene valor legal directo por no haber sido convalidado por una norma general. Sin embargo, el uso judicial y su citación constante, en primera medida por las Cortes de Apelación, luego por la Corte de Casación y finalmente por el Consejo de Estado, hicieron que la nomenclatura Dintilhac se convirtiera en el baremo único de indemnizaciones ${ }^{37}$.

De esta manera, si los jueces no estaban obligados a justificar los criterios de liquidación de la indemnización de perjuicios corporales, en la práctica, era la confrontación del caso con otras decisiones judiciales lo que impulsaba a los litigantes a solicitar la aplicación del baremo. Mientras tanto, el control de la Corte de Casación se concentraba en verificar que, una vez el juez reconoció como probado un daño en el juicio, éste proceda a su indemnización razonable. El Tribunal de Cierre reconoció entonces, en algunas decisiones, que el único criterio que podía considerarse respetuoso de un principio de razonabilidad económica y humanística era la nomenclatura Dintilhac. Hay que recordar que cuando se solicitó a la realización de la nomenclatura, el Ministerio de Justicia francés exigió la creación de una lista definitiva de perjuicios ${ }^{38}$. Para establecer esa lista todos los actores interesados en el tema fueron debidamente consultados, de forma que no podían, posteriormente desconocer su validez. De esta manera la aplicación de la nomenclatura Dintilhac se volvió incontestable no solo en la gestión de siniestros por las empresas aseguradoras, sino también en los estrados judiciales.

Vemos entonces que fue la discusión social alrededor del tema, durante los debates gremiales necesarios a la adopción de la nomenclatura Dintilhanc, lo que garantizó una nomenclatura uniforme que a la postre significó el respeto del principio de reparación integral y su corolario, el principio indemnizatorio.

Posteriormente, el derecho jurisprudencial le agregó a profundidad este baremo, al construir sobre los cimientos que así se habían creado: luego de 13 años de sentencias en perjuicios corporales las Cortes de Apelación adoptaron el referencial de liquidación de perjuicios corporales, mencionado más arriba, que define específicamente como debe ser liquidado cada perjuicio reconocido en la nomenclatura Dintilhac.

Sin embargo, a pesar de que la adopción espontánea de la nomenclatura Dintilhac mejoró la seguridad jurídica, ello no es óbice para limitar definitivamente la evolución de las nociones de perjuicios corporales. Un ejemplo de ello son los nuevos perjuicios que se han reconocido luego de los ataques terroristas, temas que abordaremos más adelante (cf. § 1.2.3.2).

\footnotetext{
37 N. Kilgus (2016). Préjudice esthétique temporaire et poste de préjudice du déficit fonctionnel temporaire, Répertoire Dalloz actualité, 22 février 2016 n 10-23.378.

38 Mission confiée au groupe de travail d'élaborer une nomenclature commune des préjudices corporels, Conseil des ministres, le 29 septembre 2004.
} 


\subsubsection{El rol de los perjuicios corporales dentro del sistema jurídico de la responsabilidad civil}

Es una dificultad propia a los daños corporales el poder determinar el monto final que corresponde de un lado, a los organismos de seguridad social, y de otro lado, al tercero responsable. En efecto, esta área del derecho está en la confluencia del derecho de la responsabilidad civil y del derecho de la seguridad social, las cuales reposan sobre lógicas diferentes ${ }^{39}$.

La nomenclatura Dintilhac incluye tipologías de perjuicios que son, total o parcialmente, objeto de indemnización por los organismos de la seguridad social y del tercero responsable y de su asegurador. La persona víctima de una lesión a su integridad física tiene derecho a la reparación integral de su perjuicio. Así, la víctima puede pretender, de un lado, a unas prestaciones en compensación del daño sufrido, compensación que es pagada por los organismos de seguridad social, y de otro lado, a una indemnización complementaria por parte del tercero responsable del daño y de su asegurador. La distinción entre esa compensación y la indemnización es delicada puesto que habrá tipologías de perjuicios que pueden ser objeto de subrogación por parte del asegurador o del organismo de seguridad social, los que pueden entonces, una vez se efectuó el pago a la víctima, solicitar un reembolso al responsable del perjuicio ${ }^{40}$.

Para dilucidar la pregunta de los límites entre la compensación de la seguridad social y las indemnizaciones propias de la responsabilidad civil, se considera que es necesario acudir a la distinción clásica entre las prestaciones asistenciales globales y la reparación de carácter indemnizatorio. Mientras que el primero tiene como fundamento un contrato o una cotización periódica, el segundo tiene su origen en la obligación de resarcimiento que surge del hecho perjudicial ${ }^{41}$. Así, la reparación global y limitada tiene su origen en la objetivación de la responsabilidad civil, principalmente en los ramos de riesgos laborales y automóviles, mientras que la reparación civil del tercero responsable sigue una lógica culpabilística ${ }^{42}$.

Un ejemplo de la aplicación de este principio lo tenemos en la Ley francesa $\mathrm{N}^{\circ} 2006$ 1640 de 21 de diciembre de 2006 sobre la financiación de la seguridad social, en la cual se estableció que la distribución de la carga indemnizatoria debe hacerse identificando específicamente cada título de perjuicio, lo cual se realiza a través de la nomenclatura Dintilhac. De esta manera, las entidades encargadas de la reparación de la víctima deben especificar cuáles son las prestaciones de la seguridad social pagadas a la víctima, lo cual permite entonces identificar por sustracción cuáles son los perjuicios que corresponden a la responsabilidad civil.

\footnotetext{
39 P. CASSON. Règles propres au dommage corporel, Dommages et intérêts: Évaluation judiciaire des dommages et intérêts, Jurisclasseur LexisNexis, Février 2017 (2019), recuperado: 13.10.2019.

${ }^{40} \mathrm{H}$. Pelosse et al. (2017). Revue des dépenses, Le recours contre tiers des caisses de sécurité sociale, Inspection générale des finances, $\mathrm{N}^{\circ}$ 2017-M-004.

41 J. Kullmann et al. (2019). Critère de qualification $n^{\circ} 18$, Partie 1 Le contrat d'assurance, Le Lamy Assurances, Wolters Kluwer.

42 Op. cit. P. CAsson (2019).
} 
Más aún, para eliminar toda duda, siguiendo una propuesta en este sentido del estudio Lambert-Faivre, el legislador decidió que cuando la reclamación en contra del tercero responsable se realiza al mismo tiempo por la víctima y por los organismos de seguridad social (en una acción subrogatoria), la indemnización de la víctima debe primar, y solo luego de ello se puede satisfacer a los organismos de seguridad social subrogados ${ }^{43}$.

\subsubsection{Aplicaciones prácticas de la nomenclatura Dintilhac}

La nomenclatura Dintilhac es usada en la reparación de perjuicios corporales que realizan las aseguradoras, específicamente a través de los Acuerdos de Indemnización existentes en Francia. Un ejemplo prominente es en el ramo automóviles (1.2.3.1). Hay además que mencionar que el sistema de indemnización instituido en la nomenclatura Dintilhac fue puesto a prueba luego de los atentados terroristas que afectaron gravemente a Francia en los últimos 4 años (1.2.3.2).

\subsubsection{Acuerdo entre losAseguradores para laIndemnización de Perjuicios Corporales en el Ramo Automóviles}

Fue gracias a la creación de la nomenclatura Dintilhac que los conflictos sobre perjuicios corporales fueron centralizados y los riesgos jurídicos pudieron ser objeto de previsiones razonables por parte de los aseguradores. Se decidió entonces, en el año 2007, establecer un acuerdo entre las Aseguradoras del Ramo Automóviles para que la indemnización de las víctimas fuera realizada de forma más expedita, al mismo tiempo que se establecieron unas reglas de juego claras para las compañías de seguros y demás entidades intervinientes.

La Convención de Indemnización y Reclamaciones en Siniestros Automovilísticos (IRCA-IRSA), busca acelerar el pago de los perjuicios corporales entre los aseguradores designando, desde el accidente, un asegurador encargado de la instrucción del caso, así como un procedimiento obligatorio de oferta de indemnización. Este acuerdo organizó el peritaje médico, integrando la nomenclatura Dintilhac como baremo de indemnización y estableció unos términos máximos para la indemnización de las víctimas. El acuerdo fijó además las reglas sobre la contribución de cada asegurador a la indemnización del siniestro.

El asegurador del primer vehículo implicado en el accidente es el designado legalmente para realizar la instrucción del caso para la indemnización definitiva de las víctimas. Si la víctima sufrió una disminución de su capacidad laboral inferior al 5\%, el asegurador designado no puede contestar su responsabilidad. Si el asegurador que, según las reglas de la responsabilidad civil, tiene la carga indemnizatoria final no se manifiesta oportunamente, no podrá entonces oponerse al monto que fue reconocido por otro asegurador más eficiente que haya asumido la instrucción del caso.

${ }^{43}$ Ibidem. 
En un lapso de 3 meses luego de la solicitud de reparación formulada por la víctima, o en un plazo máximo de 8 meses desde el accidente, el asegurador instructor debe dirigir una oferta de indemnización a las víctimas. Esta oferta, teniendo en cuenta la nomenclatura Dintilhac, es formulada según cada uno de los perjuicios corporales sufridos por las víctimas. En ausencia de oferta, una sanción consistente en la obligación de pagar el doble de la tasa de interés legal es aplicable al asegurador.

Luego de la aceptación de la oferta, el asegurador debe pagar la indemnización en un término de 48 horas. Pero si la víctima se opone al monto mencionado en la oferta, ésta puede solicitar al asegurador reconsiderar su proposición o demandarlo ante los jueces. En tal caso el pago no será realizado sino hasta la finalización del proceso judicial.

El asegurador instructor, en sus decisiones durante el procedimiento de peritaje, recolección de pruebas, coordinación con los organismos de la seguridad social y de solicitudes de pago subrogatorias, debe respetar un procedimiento de reclamación amigable y extrajudicial, que es aplicable entre los aseguradores relacionados con el accidente automovilístico. En caso de no llegarse a un acuerdo, se establece un procedimiento arbitral.

Esta convención IRCA-IRSA se considera un éxito porque el $89 \%$ de los accidentes son gestionados por esta vía. Sin embargo, es común que las víctimas consideren que la oferta es insuficiente y por ello el número de procedimientos judiciales sobre la liquidación de perjuicios corporales es todavía considerable. Como este, otros acuerdos existen entre los aseguradores para garantizar una indemnización rápida de las víctimas, específicamente en los Ramos Construcción, Incendios e Inundaciones.

\subsubsection{2.-La reparación de los perjuicios corporales luego de los atentados terroristas}

En Francia existe un Fondo de Garantía de Víctimas de Actos de Terrorismo (FGTI), cuyo objetivo es garantizar que las personas que fueron víctimas de ataques terroristas reciban una indemnización siguiendo la nomenclatura Dintilhac. La financiación del FGTI se realiza principalmente con un aumento porcentual de la prima de todos los contratos de seguros de los Ramos Automóviles y Vivienda. Solo en el año 2017 la financiación del Fondo ascendió a un total de 666,8 millones de euros, mientras que el pago de indemnizaciones se realizó por un total de 436,4 millones.

Este Fondo realiza una prestación inmediata con el objetivo de cubrir los primeros gastos médicos necesitados por el ciudadano víctima. Posteriormente es realizado un peritaje médico con el objetivo de establecer cuáles son los perjuicios sufridos según la nomenclatura Dintilhac.

En los últimos años Francia ha sido objeto de varios atentados terroristas que han gravemente afectado a la población y conmovido la conciencia de la población. A 
continuación, presentamos los siguientes sucesos que fueron los que más generaron discusiones sociales y políticas, y que ocasionaron una intervención directa por el gremio asegurador ${ }^{44}$ :

- Masacre del periódico "Charlie Hebdo" (enero 2015), 11 personas asesinadas,

- Secuestro del Supermercado HyperCacher de Vincennes (enero 2015), 4 personas asesinadas,

- Atentado en el Tren Thalys (Ámsterdam-Paris), (agosto 2015), varias personas heridas,

- Tres explosiones en el Estadio de Francia (noviembre 2015) un muerto y varios heridos,

- Ataques con tiros de fusil a varios restaurantes y bares del distrito 11 de París (noviembre 2015), 39 personas asesinadas y 34 heridos,

- Secuestros y asesinatos masivos en el Teatro Bataclan (noviembre 2015), 90 personas asesinadas y varios cientos de heridos, cuando un total de 1.500 personas asistían al evento y fueron testigos directos de los hechos presentando afectaciones psicológicas tipo "shock",

- Atentado con un camión en Niza (julio 2016), 84 decesos, 202 personas heridas, cuando un total de 30.000 personas asistían al evento y que estuvieron durante largas horas en estado de confusión, bajo gran estrés debido a los tiroteos, las ambulancias y al hecho de presenciar la violencia y los cuerpos de las personas asesinadas,

- Ataque en el mercado de navidad de Estrasburgo (diciembre 2018), 5 decesos y 11 heridos, para un evento cuya asistencia es de varios miles de personas que debieron buscar refugio y correr durante varias horas.

Estos atentados generaron entonces un número muy alto de heridos y de personas asesinadas, situación que generó gran presión sobre el Fondo de Garantía de Víctimas de Actos de Terrorismo FGTI.

De este modo, respecto del atentado de París de noviembre de 2015, un número de 2.625 víctimas fueron indemnizadas por un monto total de 88,4 millones de euros, mientras que, para el atentado de Niza de julio de 2015, un número de 2.262 víctimas fueron indemnizadas por un monto total de 46,4 millones de euros. Desde su creación, el fondo nunca había visto un tal número de solicitudes como fue el caso de los años 2015 y 2016.

Gracias a la presión de organizaciones sociales, las víctimas lograron el reconocimiento de tres nuevos tipos de daño que no estaban inicialmente concebidos en la nomenclatura Dintilhac, la cual solo hablaba del perjuicio excepcional específico de

\footnotetext{
44 Esta es una lista no exhaustiva de los hechos que deja por fuera gran cantidad de atentados que produjeron un número menor de víctimas y por lo tanto un impacto mediático menor, pero no por ello dejan de ser graves. Durante el mismo periodo, otros atentados de gran impacto tuvieron lugar en Dinamarca, Reino Unido, España y Bélgica.
} 
acto de terrorismo ${ }^{45}$. De este modo se reconocieron: 1) el perjuicio de angustia o sentimiento de muerte inminente sentido por las víctimas en el momento inmediato del atentado; 2) el perjuicio de pérdida de un familiar próximo en atentados terroristas, respecto de las víctimas indirectas; y 3) el perjuicio de incertidumbre sobre el estado de una persona luego de un atentado, respecto de las víctimas indirectas.

\section{ESTADO DEL ARTE DE LA INDEMNIZACIÓN DE PERJUICIOS CORPORALES EN COLOMBIA}

El instituto de la responsabilidad civil tiene, como finalidad principal, el resarcimiento de los perjuicios injustamente sufridos por las víctimas, a efectos de llevarlos en lo posible, al estado en el cual se encontraban antes de ser sometidos al evento dañoso. Al emprender dicha empresa se debe responder a un interrogante básico: cuáles son los daños que se reconocen en cada ordenamiento jurídico, siendo tarea del juez, en el ejercicio de la administración de justicia e inspirado bajo el principio de la reparación integral, identificar aquellas afrentas que ameritan indemnización judicial.

Al respecto, es necesario aceptar que las sociedades evolucionan constantemente y con ellas también evolucionan las dinámicas de los riesgos y perjuicios que pueden ser objeto de reconocimiento ${ }^{46}$. Dado que la loable finalidad de reparar a la víctima se realiza, en gran medida, a través de los contratos de seguro, los análisis de la presente sección se enfocarán en este tipo de contrato.

Con el propósito de realizar un análisis que converja con el previamente expuesto en Francia, abordaremos en primera medida, los presupuestos jurídicos de la reparación de perjuicios corporales en Colombia (2.1). Posteriormente mencionaremos cómo ocurre la concretización de la noción de los daños corporales en la reparación de víctimas (2.2).

\subsection{Presupuestos jurídicos de la reparación de los perjuicios corporales en Colombia}

En Colombia, los daños corporales son una institución de desarrollo mayoritariamente jurisprudencial ${ }^{47}$, que ha protagonizado diversidad de cambios, especialmente en lo atinente a tipologías de perjuicios ${ }^{48}$. Así, en primera medida referenciaremos cuál es

\footnotetext{
45 A. Coignac (2018). L'évolution de la prise en charge des victimes d'actes de terrorismo, Dalloz Actualité, 5 mars 2018.

46 Algunos mencionan que se trata de un proceso que a nivel jurídico representa una 'crisis de identidad' de la responsabilidad civil: G. Fernandez Cruz (2015). La dimensión omnicomprensiva del daño no patrimonial y la reclasificación de los daños, Revista Advocatus n³1, Asociación Civil ADV Editores, Lima. 47 Un referente de este derecho de daños de origen jurisprudencial, en el derecho administrativo ver: NAVARRETE-FríAs, Ana María (2009). La responsabilidad del Estado y su adecuación a parámetros interamericanos, Estud. Socio-Juríd., Bogotá (Colombia), 11(2): 335-376, julio-diciembre de 2009.

48 Pasando de otros, el daño a la vida de relación, el daño a la alteración de las condiciones de existencia, el daño estético y el daño psicológico, gracias una conciencia mayor sobre la dignidad humana, como lo menciona un autor: J. I. MANRIQUE NIÑo (2007) La reparación del daño antijurídico en la prestación del servicio público de la educación, Estud. Socio-Juríd., Bogotá (Colombia), 9(1): 205-246, enero-junio de 2007.
} 
la noción del perjuicio corporal en Colombia (2.1.1), para luego precisar brevemente la definición de reparación integral, principio de vital importancia en este tipo de perjuicios (2.1.2). Mencionados estos presupuestos, indicaremos como se realiza la concretización de la noción de los daños corporales en la reparación de víctimas (2.1.3).

\subsubsection{Noción jurídica del perjuicio corporal en Colombia}

El daño a la integridad física es la razón que motiva la intervención judicial para proteger a la persona ante la circunstancia dañosa. El perjuicio corporal puede entonces interpretarse, desde el punto de vista jurídico ${ }^{49}$, como el evento desencadenante de la respuesta indemnizatoria de la sociedad ante el rompimiento de la normalidad so$\operatorname{cial}^{50}$. El perjuicio corporal es uno solo, pero sus manifestaciones jurídicas son varias, pues tocan diferentes esferas y ámbitos de la vida humana ${ }^{51}$. El concepto de base es entonces el daño corporal, a partir del cual se construye el sistema de responsabilidad civil del cual sus pilares básicos son las tipologías de perjuicios.

A pesar de que se trata de un concepto esencial de la responsabilidad civil, en Colombia no puede afirmarse que las Altas Cortes hayan desarrollado una definición jurisprudencial de los perjuicios corporales. Empero, ello no significa que en ciertas sentencias no se haya hecho mención, aunque tímida, del concepto de daños corporales ${ }^{52}$.

De manera preliminar tenemos que recordar que el concepto de daño corporal pasa por otras denominaciones que se hacen en diferentes áreas jurídicas. Así, el daño corporal, se asimila conceptualmente al daño personal que es una variante de la noción de perjuicio extrapatrimonial ${ }^{53}$. Tenemos además la noción de lesiones personales, propia del derecho penal, que es también usada en la indemnización de la jurisdicción civil $^{54}$. En uno u otro caso la noción de daños corporales se les asemeja porque hace referencia a una perturbación de la integridad corporal, pero mientras que en el primer caso se refiere a una consecuencia indemnizatoria, en el segundo es la denominación penal de todo acto que comporta una afectación en el cuerpo o en la salud, de características no fatales ${ }^{55}$.

\footnotetext{
49 J.C. Henao (2015). Las formas de reparación en la responsabilidad del Estado: hacia su unificación sustancial en todas las acciones contra el Estado. Revista de Derecho Privado, (28), 277-366.

50 Michel Foucault hace una descripción de la perturbación de la normalidad social causada por el ilícito penal: M. Foucault (1973). La vérité et les formes juridiques, Dits Ecrits tome II texte ${ }^{\circ} 139$.

51 En este sentido: L. C. SÁnchez Hernández (2012). Reflexiones en torno a las funciones de la condena por daños extrapatrimoniales a la persona a partir del estudio de la "iniuria" del derecho romano clásico, Revista de Derecho Privado, Núm. 23 (2012): julio-diciembre.

52 Siguiendo en este punto la noción dada sobre las líneas jurisprudenciales por: LóPEz MedinA, Diego Eduardo. El derecho de los jueces, Legis, Universidad de los Andes, Bogotá, 2004, p. 140.

53 C.F. Sessarego (1998). Daño a la persona y daño moral en la doctrina y en la jurisprudencia latinoamericana actual, THĒMIS-Revista de Derecho, $n^{\circ} 38,1998$, Pontificia Universidad Católica del Perú.

54 Pero en cualquier caso la cuantificación de los perjuicios enseñe penal debe realizarse bajo las reglas procesales civiles, según se determinó en Corte Suprema de Justicia, Sala Penal, Sentencia SP-133002017 (50034), ago. 30/17.

55 Art. 111 Código Penal colombiano.
} 
Respecto del análisis jurisprudencial que se le ha dado a este término, tenemos en primer lugar que, en ciertos pronunciamientos, el Consejo de Estado hace mención de la noción de daño corporal, aunque realizando una exposición sucinta y fragmentada de esta, veamos:

En Sentencia de 14 de septiembre de $2011^{56}$ la Sección Tercera considera el daño corporal como un perjuicio enmarcado en el daño a la salud. Es de notar que en dicha jurisprudencia el Consejo de Estado construyó el concepto del daño corporal haciendo referencia a tipologías otrora usadas, como fueron el daño sexual, el daño psicológico y la alteración o pérdidas anatómicas o funcionales.

Pero esta línea argumentativa tiene un desarrollo inusitado con las sentencias gemelas de 28 de agosto de $2014^{57}$ en las cuales se consagró como tipología autónoma la afectación relevante a bienes o derechos convencional y constitucionalmente amparados, como una manera de tener en cuenta situaciones que no podrán ser incluidas en la denominación tradicional de daño corporal o afectación psicofísica ${ }^{58}$.

Posteriormente, en una providencia de confirmación de principio de 18 mayo de $2017^{59}$, el Consejo de Estado reconoce el daño corporal como un perjuicio proveniente de la lesión al derecho fundamental a la salud, consagrado en el artículo 49 de la Constitución Política. Cabe anotar que en las consideraciones de la Sección Tercera se hicieron múltiples referencias a las lesiones a la integridad física y psíquica. Sin embargo, en dicha ocasión el Juez Administrativo no delimitó si ambas esferas se encontraban cubiertas por la noción de daño corporal, lo cual puede tener consecuencias respecto de las coberturas de seguro ${ }^{60}$.

Más recientemente, en un caso de responsabilidad civil médica, el Consejo de Estado en Sentencia de 19 de septiembre de 2019, definió las lesiones personales como los efectos inmediatos e inmodificables en la integridad psicofísica de las personas ${ }^{61}$. Podemos concluir entonces que el rol que actualmente tiene el daño corporal en la jurisprudencia contencioso-administrativa encuentra, en gran medida, fundamento en la construcción que ha realizado el Consejo de Estado de la tipología del daño a la salud, así como las denominaciones análogas de perjuicio fisiológico y perjuicio biológico ${ }^{62}$.

\footnotetext{
${ }^{56}$ Consejo de Estado, radicación nro. 05001-23-25-000-1994-00020-01, nro. Interno 19031.

57 Consejo de Estado, Sección Tercera, sentencia de unificación jurisprudencial del 28 de agosto de 2014, Exp. 32988, M.P. Ramiro Pazos Guerrero y sentencia de 28 de agosto de 2014, exp. 50001231500019990032601 (31172), C.P. Olga Mélida Valle de la Oz.

58 Se cito como ejemplos el derecho al buen nombre, al honor o a la honra; el derecho a tener una familia, entre otros.

59 Sentencia nº5001-23-31-000-1998-04063-01 de Consejo de Estado, Sala de lo Contencioso Administrativo, Sección Tercera, de 18 de mayo de 2017.

${ }^{60}$ En efecto, podrían suscitarse diversas discusiones en materia de seguros sobre la cobertura de las lesiones a la psique, en ausencia de un daño físico o de una manifestación corpórea.

${ }^{61}$ Consejo de Estado, Sección Tercera, 19 de septiembre de 2019, CP. Marta Nubia Velásquez Rico, Rad. 52898.

62 Lo cual recuerda las denominaciones que en este sentido se realizan en Francia e Italia respectivamente:

L. C. SÁNCHEZ HERNÁNDEZ (2012). Reflexiones en torno a las funciones de la condena por daños extra-
} 
No podemos dejar de lado una importante reflexión sobre este tema realizada por un Magistrado y profesor ${ }^{63}$, quien planteando una pugna entre el otrora vigente daño a la vida de relación y a la noción de daño a la salud, mencionó que el daño corporal es una noción central para el resarcimiento de la órbita de la salud del ser humano, definida por la Organización Mundial de la Salud como "el estado completo de bienestar físico, psíquico, y social, no circunscrito a la ausencia de afecciones y enfermedades". Haciendo alusión al daño a la salud, este autor indicó que en éste se encuentran agrupadas las afectaciones físicas y psíquicas de la persona, contemplándose tanto la modificación de la unidad corporal como a las consecuencias que ésta genera, consistentes en manifestaciones de orden estético, sexual, psicológico, entre otros.

Por su parte, el análisis que realiza la Sala de Casación Civil de la Corte Suprema de Justicia es diferente al desarrollado por la jurisdicción administrativa, aunque como ésta, para dar una definición del perjuicio corporal, ha acercado este concepto de otros que pueden proveerle un contenido conceptual.

Podemos citar en primer lugar una Sentencia de 4 de abril de $1968^{64}$, en la cual la Corte Suprema reconoce que el daño a la persona es aquel que conlleva un desmedro a la integridad física o mental, o en injuria al honor, la libertad o la intimidad, susceptible de traducirse en consecuencias patrimoniales.

En una Sentencia Hito de 25 de noviembre de $1992^{65}$, la Sala Civil consideró que el juez dispone de un discreto arbitrio para valorar la existencia y cuantía de perjuicios corporales. La Corte aclara que esta prerrogativa es dada al juez al tratarse de daños en la integridad corporal que producen perjuicios inmateriales o extrapatrimoniales. Sin embargo, para la Corte, dicho arbitrio debe ejercerse con prudencia, para evitar servirse de pautas apriorísticas.

Una providencia nodal la encontramos en la Sentencia de 6 de mayo de $2016^{66}$, en la cual la Sala Civil dedujo la existencia del perjuicio corporal al valorar el estado de la víctima antes y después del accidente, según la historia clínica encontrada en el expediente de la junta de calificación.

Consideramos entonces que, en el análisis indemnizatorio, el perjuicio corporal es el precepto primario, que proviene del estudio de las lesiones en el cuerpo humano, según se registró por los servicios de salud. Luego, el juez realiza un análisis jurídico de dichas lesiones y les atribuye una indemnización. Es entonces un proceso de calificación de los hechos realizado en dos etapas diferenciadas, proviniendo de dos profesionales de áreas diferentes, médicos y abogados. Por ello es por lo que se afirma que la valoración médica del daño corporal corresponde a la historia clínica que

\footnotetext{
patrimoniales a la persona a partir del estudio de la "iniuria” del derecho romano clásico, Revista de Derecho Privado, Núm. 23 (2012): julio-diciembre.

${ }^{63}$ Aclaración de voto, Sentencia de la Sección Tercera fechada 11 de agosto de 2010, Consejo de Estado, radicado n ${ }^{\circ}$ 25000-23-26-000-1996-02533-01, Magistrado Enrique Gil Botero, p. 24.

${ }^{64}$ Sentencia de 4 de abril de 1968, cit., G.J. CXXIV, 63, citada por: Hinestrosa, F. (2017). Devenir del derecho de daños. Revista de Derecho Privado, (32), 5-26.

65 CSJ Civil sentencia de 25 de noviembre de 1992, exp. 3382.

${ }^{66}$ CSJ Civil sentencia de 6 de mayo de 2016, n ${ }^{\circ}$ SC5885-2016.
} 
refleja las consecuencias de un suceso traumático "sobre la integridad psicofísica y la salud de una persona, con la finalidad de obtener una evaluación final que permita al juzgador establecer las consecuencias exactas del mismo"67. Así, según la Sala Penal en Sentencia de 30 de agosto de 2017, los jueces cuentan con plenas potestades probatorias para valorar la lesión corporal, más particularmente con la incorporación de documentos como la historia clínica y las evaluaciones de Medicina Legal ${ }^{68}$. De igual forma, como se decidió en Sentencia de la Sala Civil de 30 de septiembre del 2016, la falta de valoración del expediente médico es razón suficiente para censurar la decisión tomada por los jueces de instancia ${ }^{69}$.

La distinción de estas dos etapas tiene importancia puesto que, aun si la definición dogmática del perjuicio corporal no genera inconvenientes particulares, su articulación es delicada cuando el juez se confronta a un caso en el cual el momento de configuración del daño y la magnitud de este no son fácilmente identificables. Es en efecto el caso juzgado por el Consejo de Estado en Sentencia de 3 de mayo de $2018^{70}$, en la cual la configuración del perjuicio se consideró ocurrida posteriormente a la expedición del dictamen de pérdida de capacidad laboral puesto que, a voces de los Consejeros, hay eventos de lesiones personales en los cuales no es fácil determinar a ciencia cierta el momento exacto en que se produce el daño por la ausencia de una manifestación externa del mismo y por las posibilidades de agravación.

De otro lado, bajo el imperio de la clasificación tradicional en perjuicios patrimoniales y extrapatrimoniales, pareciese que se hubiera desvanecido la relevancia de la noción daño corporal para los perjuicios materiales, en el sentido en que era reconocido por la doctrina ${ }^{71}$ y por la jurisprudencia en providencias de antaño, como fuente u origen de perjuicios resarcibles de diverso orden, incluso económico (v.gr. daño emergente o lucro cesante).

Un ejemplo de ello son los denominados gastos de adaptación de la vivienda y gastos de adaptación del vehículo a la persona en condición de discapacidad, los cuales, como perjuicios patrimoniales derivados de daño corporal, podrían gozar de reconocimiento y reparación en el ordenamiento jurídico colombiano, sin embargo, constituyen rubros aún desconocidos o, por lo menos, poco explorados por los órganos jurisdiccionales de cierre colombiano.

Así las cosas, surge la pregunta de saber si se debe instituir un sistema de calificación por perjuicios en el ordenamiento jurídico colombiano, con el propósito de abarcar las diversas manifestaciones dañosas en las víctimas o si, por el contrario, el esquema vigente es solvente para cumplir este propósito. No se puede perder de vista la labor

\footnotetext{
${ }^{67}$ E. Gil Botero (2012). El daño a la salud en Colombia-retos frente a su delimitación, valoración y resarcimiento. Revista Digital de Derecho Administrativo. 8 (dic. 2012), 89-145.

${ }^{68}$ CSJ Sala Penal, Sentencia de 30 de agosto de 2017, SP134512017 (48231).

${ }^{69}$ Sentencia de 30 de septiembre del 2016 SC13925-2016, nº 05001-31-03-003-2005-00174-01, M.P. Ariel Salazar Ramírez.

${ }^{70}$ Consejo de Estado Sección Segunda, Sentencia 11001031500020180073700, may. 3/18, CP. Gabriel Valbuena Hernández.

${ }^{71}$ Henao, J.C. (1998). El Daño (segunda reimpresión: abril de 2007). Colombia: Universidad Externado de Colombia.
} 
esencial que cumple el abogado que representa a las víctimas, quien debe lograr identificar y probar los daños sufridos por las víctimas, sorteando la dificultad que representa obtener una decisión razonable y oportuna por parte de la junta de calificación de pérdida de capacidad laboral.

Sin embargo, resultaría un ejercicio enriquecedor para el resarcimiento de las víctimas, el dotar a la noción de daño corporal del protagonismo que tiene en otros países, como fuente de diversidad de perjuicios. Ya sea para identificar en las tipologías actualmente utilizadas en Colombia rubros que han permanecido ocultos a la solicitud de las partes y el consecuente reconocimiento por los jueces o, en caso de no enmarcarse en ninguna de las clasificaciones de actual usanza, para inspirar cambios jurisprudenciales o legislativos.

\subsubsection{El Principio de Reparación Integral enel ordenamiento jurídico colombiano}

El principio de reparación integral, inicialmente ${ }^{72}$ consagrado en el artículo 16 de la Ley $N^{\circ} 446$ de $1998^{73}$, constituye un parámetro guía en la mayoría de las Sentencias emitidas por las Altas Cortes colombianas. Los jueces de instancia deben abordar la compleja tarea de definir las tipologías de daños objeto de resarcimiento por el ordenamiento jurídico, con miras a cumplir tres propósitos: primero, determinar cuáles son las circunstancias que se incluyen en una categoría de perjuicio, delimitando su definición; segundo, excluyendo algunos hechos que no pueden ser asumidos dentro de un tipo de perjuicio; y tercero, dar cuenta de la evolución social y reconocer, de ser necesario, nuevos daños.

Este principio supone, en palabras del Consejo de Estado ${ }^{74}$, una obligación en cabeza del juez, quien, a la luz de los cánones y principios constitucionales, debe velar por la justa y correcta medición del daño, para garantizar así la indemnización plena, sin que ello se traduzca en un enriquecimiento injustificado de la víctima. Esta posición se esgrime bajo la fuerte influencia del derecho constitucional en el ordenamiento jurídico colombiano, en el cual la victima adquiere un papel protagónico como titular derechos e intereses que deben ser protegidos y efectivamente reparados, en aquellos eventos que presenten lesiones injustificadas o antijurídicas ${ }^{75}$.

Similar premisa es defendida por la doctrina, la cual predica que, en virtud del principio de reparación integral, toda ofensa contra un interés legítimo protegido por el ordenamiento jurídico debe ser objeto de reparación ${ }^{76} \mathrm{y}$, consecuentemente, es deber

\footnotetext{
${ }_{72}$ Un referente legislativo anterior es el art. 2357 del Código Civil, que permite la reducción de la indemnización únicamente si la víctima fue imprudente.

73 “Art. 16. Valoración de daños. Dentro de cualquier proceso que se surta ante la Administración de Justicia, la valoración de daños irrogados a las personas y a las cosas, atenderá los principios de reparación integral y equidad y observará los criterios técnicos actuariales".

${ }^{74}$ Sentencia de 14 de septiembre de 2011, Sección Tercera nº5001-23-31-000-2007-00139-01(38222),

C.P.: Enrique Gil Botero.

${ }^{75}$ Ibídem, p. 20.

${ }^{76}$ L. C. SÁnChez HeRnández (2012). Reflexiones en torno a las funciones de la condena por daños ex-
} 
del juez superar el velo que pueda cubrir los daños sufridos por la víctima y categorizarlos con miras a su resarcimiento efectivo ${ }^{77}$.

Recordemos que el principio a la reparación integral, en palabras de la Corte Suprema de Justicia ${ }^{78}$, debe inspirar a los jueces a reconocer en forma prudente y razonada nuevas clases de perjuicios resarcibles encaminados a salvaguardar los derechos de las víctimas. Esto toda vez que el juzgador debe ser consciente de las necesidades de la época y de las circunstancias propias del país que imponen la necesidad de que las instituciones jurídicas se transformen, especialmente el derecho de daños, que es de desarrollo mayoritariamente jurisprudencial.

A pesar de la oposición a la aplicación del principio de reparación integral ${ }^{79}$, es evidente que se trata no solo de una regla propia de la dogmática jurídica del derecho privado, sino también de un concepto primigenio de la responsabilidad civil ${ }^{80}$ que solo encontraría limitación bajo el criterio de razonabilidad en la forma en que éste es comprendido por la Corte Constitucional colombiana ${ }^{81}$. La reparación integral permite al juez acudir al criterio de equidad, al principio pro damnato y a la justicia distributiva $^{82}$ para estimar el monto que puede reparar los daños extrapatrimoniales, que por definición no pueden ser objeto de cálculo a través de una fórmula matemática. Concebido de esta manera, el principio de reparación integral puede mejorar la suerte de la víctima, no como una sanción del agente, sino como una consecuencia del hecho de que todo daño, independiente de si es cuantificable o no, debe ser reparado ${ }^{83}$. No es válido entonces afirmar, como lo hace un autor ${ }^{84}$, que un perjuicio no se puede reparar porque, en la práctica puede constituir una sanción o un daño punitivo. La discusión debería girar hacia la creación de sistemas de indemnización, más allá que querer reducir el ámbito de la noción de la responsabilidad civil, pues ello no responde a un criterio de especialización de la justicia y corresponde más a los ordenamientos jurídicos en estados primarios de desarrollo en las cuales no existe suficiente penetración de servicios de seguros, ni esquemas jurídicos de garantía para las víctimas.

trapatrimoniales a la persona a partir del estudio de la "iniuria" del derecho romano clásico, Revista de Derecho Privado, Núm. 23 (2012): julio-diciembre.

77 J. TAMayo Jaramillo, et al. (2017) Nuevas reflexiones sobre el daño. Colombia. Legis.

78 Corte Suprema de Justicia, Sentencia del 01 de 13 de mayo de 2008 (exp. 1100131030061997-09327), p. 57.

79 Citando a C. Bernal Pulido, J. Tamayo Jaramillo (2015). El desborde de las condenas contra el Estado, Periódico Ámbito Jurídico, 28 de marzo del 2016.

80 Actualmente en el ordenamiento colombiano la responsabilidad civil es un derecho fundamental respecto de las victimas del conflicto armado y los afectados por graves violaciones de los derechos humanos o del Derecho Internacional Humanitario, Corte Constitucional, Sentencia C-753 de 2013.

81 Según el tipo de responsabilidad, el legislador puede determinar la aplicación de ciertas limitaciones a la reparación de perjuicios: Corte Constitucional, Sentencia C916 de 2002.

82 Solarte Rodríguez, A. (2017). El principio favor victimae y su aplicación en el derecho colombiano, Anuario de Derecho Privado, 2017 Facultad de Derecho, pp. 257-304.

${ }^{83}$ GARRIDO, D. A. S. (2013). Reparación integral y responsabilidad civil: el concepto de reparación integral y su vigencia en los daños extrapatrimoniales a la persona como garantía de los derechos de las victimas. Rev. Derecho Privado, 25, 237.

84 S. RoJas QuiÑones. ¿Hacia una "nueva” responsabilidad civil?, Periódico Ámbito Jurídico, 23 de febrero del 2017 y S. RoJAs QuiÑNes ¿Cómo se debe cuantificar el daño según el Consejo de Estado y la Corte Suprema? (Parte I), Periódico Ámbito Jurídico 07 de noviembre del 2014. 


\subsection{Concretización de la noción de los daños corporales en la reparación de víctimas}

Una vez verificados los elementos de la perturbación de la integridad corporal sufrida por la víctima, se procede a determinar la reparación que exige un proceso de calificación jurídica a través de las tipologías reconocidas por los jueces colombianos (2.2.1). La concretización de la reparación de los perjuicios corporales realizada a través de los contratos de seguro exige además mencionar ciertos elementos propios a esta área del derecho (2.2.2).

\subsubsection{Caracterización de las tipologias reconocidas por la Corte Suprema de Justicia y el Consejo de Estado}

El ordenamiento jurídico colombiano no integra una lista limitada de daños resarcibles, como ocurre en otros países. Sin embargo, en la jurisprudencia reciente de la Corte Suprema de Justicia y del Consejo de Estado se pueden identificar dos clasificaciones, las cuales, a pesar de tener tipologías comunes, gozan de algunas disparidades ${ }^{85}$.

En primer lugar, tenemos que mencionar que los perjuicios materiales guardan identidad en la jurisdicción civil y en la contencioso-administrativa, reconociéndose como tipologías indemnizables el Lucro Cesante y el Daño Emergente ${ }^{86}$. No obstante, el consenso conceptual existente respecto de este perjuicio, algunas manifestaciones de esta tipología parecieran permanecer ocultas a la jurisprudencia nacional, a pesar de gozar de expreso reconocimiento en otros ordenamientos jurídicos, especialmente en lo que atañe a perjuicios consecuenciales a daños corporales.

Ahora, frente a los perjuicios extrapatrimoniales, un antecedente legislativo lo encontramos en el Decreto 1260 de 1970 en cual se impuso reparación de los daños por indebido uso del nombre, incluyendo de forma expresa la indemnización de los perjuicios no patrimoniales. Más recientemente, el legislador colombiano, en la reglamentación de la actividad del avaluador en seguros contenida en el Decreto 556 de 2014 reglamentario de la Ley N ${ }^{\circ} 1673$ e 2013 los definió como “intangibles especiales”.

Sin embargo, este tipo de perjuicios han tenido un protagonismo más marcado en la jurisprudencia. Nuestra tradición republicana bicentenaria los menciona desde las jurisprudencias Rosazza de 1896 y Villaveces de $1922^{87}$, aunque la denominación de perjuicios 'extrapatrimoniales' ha sido criticada por su imprecisión, al querer incluir en ésta todo tipo de daños que no podían ser objeto de una valoración económica ${ }^{88}$.

\footnotetext{
${ }^{85}$ En el presente escrito, sin adentrarse en las discusiones que le rodean, se hará referencia tanto la clasificación de perjuicios materiales e inmateriales, en analogía a la clasificación de patrimoniales y extrapatrimoniales, ante la común usanza de la primera por parte del Consejo de Estado y de la segunda por la Corte Suprema de Justicia.

${ }^{86}$ Recordemos que el Daño Emergente y el Lucro Cesante gozan de expresa consagración en los arts. 1613 de 1614 del Código Civil, los cuales ilustran en el marco de las obligaciones el contenido de cada uno.

${ }^{87}$ Mencionadas en: M. A. Aramburo (2018). ¿Villaveces o Rosazza? Una hipótesis sobre el daño moral, Periódico Ámbito Jurídico, 6 de julio del 2018, Bogotá.

88 E. CORTÉs (2009). Responsabilidad civil y daños a la persona, Ed. Universidad Externado de Colombia.
} 
Por ello, para dar cuenta de esta evolución de los perjuicios extrapatrimoniales, o por lo menos de los daños que no tienen un contenido material ${ }^{89}$, debemos mencionar cual ha sido el discurrir argumentativo de la Corte Suprema de Justicia (2.2.1.1), para luego analizar cuál ha sido el debate en el Consejo de Estado (2.2.1.2).

\subsubsection{Los Perjuicios Inmateriales en la Jurisdicción Civil}

El daño moral es el principal perjuicio extrapatrimonial reconocido desde larga data en Colombia ${ }^{90}$. La definición reciente de la Sala de Casación Civil es

"la lesión de la esfera sentimental y afectiva del sujeto, 'que corresponde a la órbita subjetiva, íntima o interna del individuo', que se traduce en el dolor, la pesadumbre, perturbación de ánimo, el sufrimiento espiritual, el pesar, la congoja, aflicción, sufrimiento, pena, angustia, zozobra, desolación, impotencia u otros signos expresivos" ${ }^{\prime 91}$.

En segundo lugar, se encuentra el daño a la vida en relación, tipología autónoma e independiente al daño moral, que ha sido objeto de profundo debate en cuanto a su denominación y contenido. A pesar de haber sido mencionado en una providencia del año $1968^{92}$, este perjuicio permaneció oculto a los jueces hasta el año de 1993, cuando se incorporó por parte del Consejo de Estado a la lista de perjuicios objeto de indemnización en el ordenamiento jurídico colombiano ${ }^{93}$.

No obstante, transcurrieron más de quince años para que la jurisdicción civil se viese permeada de las nuevas tipologías de perjuicios extrapatrimoniales ${ }^{94}$, en virtud de la sentencia de 13 de mayo de 2008, en la cual la Corte Suprema de Justicia reconoció el daño a la vida de relación en complemento al daño moral ${ }^{95}$. En esta providencia se hizo especial énfasis en las características del daño a la vida de relación, con el fin de deslindarlo del daño a la salud, perjuicio que para entonces tenía difusión en la jurisprudencia contencioso-administrativa.

Más recientemente, en Sentencia de 19 de diciembre de $2017^{96}$, el Tribunal de Casación afirmó que, a diferencia del daño moral, que corresponde a la órbita subjetiva,

\footnotetext{
${ }^{89}$ D. A. Sandoval Garrido (2013). Reparación integral y responsabilidad civil: el concepto de reparación integral y su vigencia en los daños extrapatrimoniales a la persona como garantía de los derechos de las víctimas. Revista de Derecho Privado, Universidad Externado n²5 (dic. 2013), 237-273.

90 Jaramillo Sierra, Camila and Robles Bacca, Paula Natalia. La reparación del daño extrapatrimonial a la persona por incumplimiento contractual: la experiencia colombiana. Revista de Derecho Privado [1998], 2014, p. 499.

${ }_{91}$ Corte Suprema de Justicia, Sentencia No. 11001-31-03-003-2003-00660-01 de 5 de agosto de 2014, p. 30.

92 Sentencia de 4 de abril de 1968, cit., G.J. CXXIV, 63, citada por: Hinestrosa, F. (2017). Devenir del derecho de daños. Revista de Derecho Privado, (32), 5-26.

${ }_{93}$ Consejo de Estado, Sección Tercera en sentencia del 1 de julio de 1993, exp. 7772.

94 L. C. SÁnChez HeRnÁNDEZ (2012). Reflexiones en torno a las funciones de la condena por daños extrapatrimoniales a la persona a partir del estudio de la "iniuria" del derecho romano clásico, Revista de Derecho Privado, Núm. 23 (2012): julio-diciembre.

95 Corte Suprema de Justicia, Sala de Casación Civil, Sentencia de 13 de mayo de 2008, Exp. 11001-3103006-1997-09327-01.

${ }_{96}$ Corte Suprema de Justicia, Sala Civil, Sentencia de 19 de diciembre de 2017, SC-220362017 (73001310300220090011401).
} 
íntima o interna del individuo, el daño a la vida de relación constituye una afectación a la esfera exterior de la persona, que puede verse alterada a causa de una lesión infligida a los bienes de la personalidad o a otro tipo de intereses jurídicos. Así, para la Corte, dentro de este tipo de daño se incluye la afectación emocional que genera la pérdida de la posibilidad de ejercer ciertas actividades que hacen más agradable la existencia, como las actividades lúdicas y recreativas, entre otras.

En tercer lugar, en Sentencia fundadora de línea de 5 de agosto de 2014, la Corte Suprema de Justicia reconoció como un daño resarcible la lesión o vulneración de los derechos humanos fundamentales ${ }^{97}$. La Corte aceptó que la lesión de cada bien de la víctima debe ser objeto de una indemnización propia y diferenciada, aun si un solo hecho dañino dio lugar a la afectación de varios de esos bienes jurídicamente tutelados de una misma víctima. En su razonamiento, la Sala Civil critica la limitación del daño extrapatrimonial a la esfera interna del sujeto, en tanto niega la tutela judicial a las repercusiones sociales del perjuicio no patrimonial, tales como la honra, la dignidad, la libertad y el buen nombre de la persona, que no dependen de su psiquis o interioridad, ni mucho menos de las consecuencias nocivas que llegue a producir en otros bienes jurídicos de inferior jerarquía.

Posteriormente, en Sentencia de 30 de septiembre del 2016 ${ }^{98}$, la Sala Civil mencionó que un derecho fundamental es un bien jurídico que goza de protección por el ordenamiento positivo, por lo que posee contenido sustancial y su quebranto apareja la consecuente indemnización de perjuicios en razón del postulado general de no causar daño a la persona o los bienes ajenos ${ }^{99}$. Para sustentar la legitimidad de este nuevo perjuicio, indica la Corte que es una consecuencia de la constitucionalización del ordenamiento jurídico aparejado a la aplicación del principio de reparación integral ${ }^{100}$.

Sin embargo, este precedente ha sido relativamente morigerado con la Sentencia nodal de 19 de diciembre de $2018^{101}$, en la cual la Corte Suprema de Justicia, a pesar de haber reconocido la existencia de unos perjuicios relevantes no susceptibles de valoración económica que sufre la persona en sus derechos fundamentales, no los indemnizó de forma autónoma e independiente, sino que autorizó un aumento porcentual del monto correspondiente al daño a la vida de relación. Así, la Sala Civil no echó

\footnotetext{
${ }_{97}$ Corte Suprema de Justicia - No 11001-31-03-003-2003-00660-01 de 5 de agosto de 2014.

98 Sentencia de 30 de septiembre del 2016, SC13925-2016, nº 05001-31-03-003-2005-00174-01, M.P. Ariel Salazar Ramírez.

99 La Corte se refiere de manera positiva sobre el nuevo perjuicio en un obiter dicta del estudio del daño que hace en la Sentencia. Sin embargo, en dicha ocasión la condena se limitó a los perjuicios materiales y al daño moral, sin que sea claro si el nuevo perjuicio lo incluyó en el monto por daño moral, o si dicho perjuicio no se presentó en el caso de instancia.

${ }^{100}$ La Corte no duda así en afincarse en el neoconstitucionalismo contemporáneo frente a aquellos que se muestran reticentes a la constitucionalización del derecho colombiano e incluso a la aplicación de un principio primigenio del derecho civil continental como lo es la reparación integral. Es el caso de un autor que afirma: "el concepto de reparación integral es imposible de delimitar en materia de perjuicios extrapatrimoniales. El Consejo de Estado, cada día con más vehemencia, otorga cifras astronómicas por este concepto, como si la reparación integral no tuviera límites" J. TAMAYO JARAMILLO (2015). El desborde de las condenas contra el Estado, Periódico Ámbito Jurídico, 28 de marzo del 2016.

101 Corte Suprema de Justicia, Sentencia de 19 de diciembre de 2018, SC5686-2018 0573631890012004 00042 01, M.P. Margarita Cabello Blanco.
} 
para atrás el reconocimiento de unos daños provenientes de la violación de derechos constitucionales, pero los incluyó bajo la óptica del daño a la vida de relación ${ }^{102}$.

Esta ralentización en la protección de las victimas hubiera podido predecirse pues en el seno de la propia Corte el reconocimiento de los nuevos perjuicios fue objeto de contestación. En las aclaraciones de voto de la Sentencia de 5 de agosto de 2014 algunos Magistrados habían reprochado la creación de una subespecie del daño no patrimonial, cuando lo coherente y razonable, en su modo de ver, hubiera sido mantener las tipologías tradicionalmente reconocidas, y endilgar responsabilidad mediante la "responsabilidad por agresión a los derechos fundamentales". En criterio de los Magistrados, se debió dar pie a la responsabilidad en ese caso concreto, pero no aparejado del resarcimiento pecuniario del buen nombre como un perjuicio inmaterial autónomo, sino enmarcando la reparación en las tipologías de daños vigentes, añadiendo -en virtud de la particularidad del derecho lesionado- un reconocimiento complementario de la reparación de satisfacción o simbólica, junto a la garantía de no repetición.

\subsubsection{Los Perjuicios Inmateriales en la Jurisdicción Contencioso-Administrativa}

La Jurisprudencia asociada al daño moral que ha elaborado el Consejo de Estado, no dista de las providencias emitidas en la materia por la Corte Suprema de Justicia en lo que atañe a la noción del perjuicio y su contenido. Recordemos que el daño moral está definido por la jurisprudencia del Consejo de Estado como el dolor, la aflicción y en general los sentimientos de desesperación, congoja, desasosiego, temor, zozobra, entre otros, que invaden a la víctima directa o indirecta de un daño antijurídico, individual o colectivo ${ }^{103}$.

En una primera etapa el Consejo de Estado diferenció, a efectos de estimar qué criterios utilizar para reconocer el daño moral, si la víctima directa había sufrido una lesión grave o leve. En el primer evento, es decir, en que se sufriese una lesión grave, se presumían los perjuicios de las víctimas indirectas, razón por la cual procedía la indemnización de éstas cuando se acreditaba, de un lado, la lesión sufrida por la víctima directa y el parentesco de este con las víctimas de rebote, de otro. En el caso contrario, cuando se trataba de lesiones leves, se debía acreditar, además del agravio sufrido por la víctima directa, el daño moral de las víctimas indirectas.

\footnotetext{
102 Aunque la Corte va más allá en sus críticas al nuevo perjuicio y menciona que no se puede equiparar el daño resarcible con la mera violación de los derechos fundamentales, pues no es la trasgresión (hecho dañoso) en sí misma lo que se indemniza o sanciona a modo de daño punitivo, sino la lesión antijurídica acreditada y derivada de esa vulneración (lo que propiamente se ha dado en llamar perjuicio). De otro modo, afirma la Corte, la prosperidad de una acción de tutela aparejaría de modo inexorable la configuración y subsecuente cobro del resarcimiento por un daño extrapatrimonial (Sentencia de 19 de diciembre de 2018, SC5686-2018).

103 Consejo de Estado, Sección Tercera, sentencia de 28 de agosto de 2014, exp. 50001231500019990032601 (31172), C.P. Olga Mélida Valle de la Oz.
} 
Este criterio fue modificado por el Consejo de Estado en el Documento Final, "Referentes para la Reparación de Perjuicios Inmateriales" de 28 de agosto de $2014^{104}$. De un lado se superó la dicotomía existente entre lesiones leves y graves, para dar paso a la pérdida de capacidad laboral de la víctima directa como criterio orientador de la cuantificación de la indemnización a la que tiene derecho, así como la correspondiente a las víctimas indirectas o de rebote.

A diferencia de daño moral que ha tenido un desarrollo relativamente pacífico en la jurisprudencia contencioso administrativa y que se ha visto aparejado de una fundamentación que se aprecia uniforme en el tiempo, las otras tipologías que se enmarcan en los perjuicios de naturaleza inmaterial han sido objeto de un profundo análisis y debate por parte del Consejo de Estado, que a lo largo de los últimos años se ha visto abocado a reflexionar sobre las categorías de usanza, específicamente el perjuicio fisiológico, el daño a la vida en relación y el daño biológico, entre otros.

Como se expresó anteriormente, los perjuicios inmateriales ajenos al daño moral permanecieron ocultos en la jurisprudencia colombiana hasta 1993, año en el cual se dio pie al reconocimiento del perjuicio fisiológico como un daño indemnizable y autónomo. Este gran paso en el derecho de daños colombiano se dio mediante sentencia proferida por el Tribunal Administrativo de Antioquia de 3 de julio de $1992^{105}$ y ratificada en sede de apelación por la Sección Tercera en sentencia de $1^{\circ}$ de julio de $1993^{106}$, que consignó como resarcible el daño fisiológico o el también denominado por la doctrina francesa préjudice d'agrément. En un fallo de 6 de mayo de $1993^{107}$, la Sección Tercera dotó de contenido a esta tipología, definiéndola como la reparación de la imposibilidad de realizar otras actividades vitales, que, aunque no producen rendimiento patrimonial, hacen agradable la existencia.

A lo largo de los años se dio pie a múltiples posiciones jurisprudenciales, reconociéndose perjuicios de diversa denominación como el daño fisiológico, a la vida en relación o la alteración a las condiciones de existencia, para finalmente aterrizar sus consideraciones en la tipología de daño a la salud ${ }^{108}$, que fue definida por el Consejo de Estado como une afectación a la integridad psicofísica, definición que recogía los perjuicios analizados en otras épocas de manera separada y autónoma como el perjuicio físico, psicológico, sexual, entre otros. Se reconoció así -en palabras del Órgano Colegiado"una valoración del daño a la persona estructurado sobre la idea del daño corporal, sin tener en cuenta categorías abiertas que distorsionen el modelo de reparación integral" 109 .

Ahora bien, el Consejo de Estado realizó un amplio análisis en sus recientes jurisprudencias con el fin de sistematizar con claridad el daño a la salud como perjuicio extrapatrimonial que reúne aquellas lesiones a la integridad corporal, psicológica, sexual o es-

\footnotetext{
104 Ibidem.

105 M.P.: Humberto Cárdena, exp. 25878.

106 Consejo de Estado, exp. 7772.

107 Consejo de Estado, exp. 7428.

108 Un recuento integral de esta línea jurisprudencial en: E. GiL Botero (2012). El daño a la salud en Colombia-retos frente a su delimitación, valoración y resarcimiento. Revista Digital de Derecho Administrativo. 8 (dic. 2012), 89-145.

109 Consejo de Estado, Sección Tercera, sentencia del 14 de septiembre de 2011, exp. 19031, p. 42.
} 
tética, acompañando así el tradicional daño moral como prejuicio que buscar satisfacer la indemnización de la órbita interna y aflictiva del ser humano. Sin embargo, se debe resaltar que la Alta Corporación dejó abierta la puerta al resarcimiento de las lesiones a los demás bienes, derechos o intereses jurídicos que las víctimas puedan acreditar, daños que se deben considerar autónomos e independientes a las tipologías antes citadas, como ocurre -en criterio del Consejo de Estado- con la lesión al buen nombre.

De esta premisa surge una nueva tipología reconocida en la jurisdicción contenciosoadministrativa y denominada "lesiones a bienes, derechos o intereses legal o convencionalmente protegidos". Al igual que en la categoría análoga reconocida por la Corte Suprema de Justicia, esta tipología trae consigo un amplio abanico de manifestaciones dañosas que pueden ser objeto de tutela por el ordenamiento jurídico colombiano. Sin embargo, para el Consejo de Estado, en principio, sólo procede su reconocimiento en casos de "violaciones relevantes" y su resarcimiento a favor de las víctimas se debe realizar con medidas de reparación no pecuniarias, salvo casos excepcionales en que dichas medidas sean insuficientes o no sean posibles para consolidar la reparación integral, circunstancia ante la cual se debe otorgar una indemnización monetaria a favor de la víctima directa ${ }^{110}$.

Empero, en una Providencia nodal de 12 de junio de 2018, el Consejo de Estado delimitó la amplitud de este concepto. La Sección Tercera aclaró que, si bien el daño fisiológico puede encontrarse subsumido en la afectación a bienes constitucional y convencionalmente protegidos, cuando el dictamen de Medicina Legal no menciona que el paciente quedó con secuelas, la lesión no reviste una gravedad tal que permita acceder al reconocimiento del perjuicio consistente en la afectación de los derechos convencional y constitucionalmente amparados. Se concluye entonces que, si bien la afectación de bienes constitucionales tiene vocación a cubrir variadas situaciones dañosas, la perturbación psicofísica en cualquier caso debe ser probada.

\subsubsection{Elementosjuridicos de la indemnización de perjuicios corporales a través de los contratos de seguro del mercado colombiano}

Dos temas de relevancia para analizar la reparación de perjuicios corporales a través de los contratos de seguro pueden ser mencionados. De un lado, la definición que se le da a este tipo de daños en los contratos colombianos de seguro (2.2.2.1), así como, de otro lado, los acuerdos entre aseguradores para la indemnización (2.2.2.2).

\subsubsection{La noción de daños corporales en las pólizas de seguro del mercado colombiano}

Al emprenderse el análisis de algunas de las condiciones generales de las pólizas de responsabilidad civil que se ofertan en el mercado colombiano, puntualmente en las

${ }_{110}$ Consejo de Estado, Sección Tercera, sentencia de unificación jurisprudencial del 28 de agosto de 2014, Exp. 32988, M.P. Ramiro Pazos Guerrero. 
pólizas de amplia comercialización (v.gr. Seguro de Responsabilidad Civil Extracontractual General, Seguro de Responsabilidad civil por Predios Labores y Operaciones, entre otros), se evidencia el uso de una gran diversidad de términos con el objetivo de delimitar el alcance de las coberturas, especialmente con la consigna de exclusiones atinentes a la naturaleza de perjuicios o de consecuencias dañosas.

Constantemente se incluyen en las pólizas los términos de "daño corporal" o de "lesiones corporales", en contraposición al daño material como criterio modulador de la cobertura, partiendo de la distinción tradicional del derecho de seguros entre los perjuicios asociados a daños corporales y a perjuicios por daños a los bienes o las cosas. Sin embargo, esta no es una clasificación de común usanza en la jurisprudencia colombiana en materia de responsabilidad civil, la cual parte de la tradicional bifurcación entre perjuicios patrimoniales y extrapatrimoniales, o materiales e inmateriales, respectivamente.

Hasta cierto punto, existe una heterogeneidad conceptual en los contratos de seguro respecto a la definición del daño corporal, pues a pesar de pretender buscar un mismo propósito de delimitación, no se coincide en los términos y nociones usados. A modo ilustrativo, con un propósito común o cercano se identifican en los condicionados generales conceptos como: lesiones corporales ${ }^{111}$, daños físicos ${ }^{112}$, daños personales ${ }^{113}$ y lesiones personales ${ }^{114}$.

Vale la pena cuestionarse cuál sería la regla a adoptar por los jueces ante controversias de cobertura que giren en torno de la noción de daño corporal. ¿Qué bases se tomarán para resolver la disputa? Probablemente estas tendrán origen doctrinal en ausencia de un número suficiente de pronunciamientos que determinen cuál es la noción del daño corporal diferenciándolo de sus consecuencias, como son los perjuicios extrapatrimoniales. Podemos citar como referente una Sentencia arquimédica de 17 de diciembre de $2017^{115}$, en la cual la Corte Suprema de Justicia conceptuó que la garantía de los perjuicios patrimoniales en el seguro de responsabilidad comprende también los perjuicios extrapatrimoniales, de manera que cuando éstos no se mencionan como

\footnotetext{
111 Allianz Seguros S.A., Seguro de Responsabilidad Civil Extracontractual General (Condicionado 24/11/2016-1301-P-06-Rce100 V3).

Aseguradora Solidaria De Colombia Entidad Cooperativa., Seguro de Responsabilidad Civil Extracontractual (condicionado 16/03/2018-1502-P-06-GENER-CL-SUSG-04-DROI SBS Seguros Colombia S.A., Seguro De Responsabilidad Civil Extracontractual (Condicionado 21032018-1322-P-06-RESP_CIVILEXTRAC-D00I).

112 Axa Colpatria Seguros S.A., Seguro de Incendio-Alianzas Pyme Protegida (Condicionado 28/07/2017-1306-Nt-P-07-P/0831julio/2017). Liberty Seguros S.A., Seguro de Responsabilidad Civil Extracontractual General (Condicionado 26/11/2016 - 1333-P-06-Rc-02).

113 La Previsora S.A. Compañía De Seguros, Seguro De Responsabilidad Civil Extracontractual (condicionado 30/12/2013-1324-P-06-Rcp016v4) La Equidad Seguros Generales Organismo Cooperativo, Seguro de Responsabilidad Civil Extracontractual (Condicionado 15062010-1501-P-06-0000000000001001).

114 Seguros Del Estado S.A., Seguro De Responsabilidad Civil Extracontractual (Condicionado 26/11/20161329-P-06-Erce003a). La Previsora S.A. Compañía De Seguros, Seguro De Responsabilidad Civil Extracontractual (condicionado 01/08/98 - 1324 - P - 00 - Pyme002). Seguros Generales Suramericana S.A., Seguro de Responsabilidad Civil por Daños a Terceros (Condicionado F-01-13-066).

115 Corte Suprema de Justicia, Sala Civil, Sentencia de 12 de diciembre de 2017 nSC-209502017 (05001310300520080049701).
} 
expresamente excluidos en la póliza de seguro de responsabilidad civil, los perjuicios no-patrimoniales se entienden amparados. La labor es entonces delicada para los equipos de suscripción si se tiene en cuenta las cuantías que pueden adquirir en algunos casos los perjuicios extrapatrimoniales.

El asegurador es el experto por excelencia de todas las aleas, pero solo hay una que escapa de su potestad actuarial: el riesgo de interpretación judicial extensiva. En efecto, ante términos usados en las pólizas que no gozan de una definición correspondiente en el lenguaje común, o que usan una definición que no es acorde a la que es dada por los tribunales, un espacio de discrecionalidad será innecesariamente creado, el cual jugará indefectiblemente a favor del asegurado en una confrontación con el asegurador en los tribunales ${ }^{116}$. De esta manera, puesto que no puede decirse perentoriamente, que a la luz de la jurisprudencia la noción de daños corporales es de orden público, las pólizas pueden delimitar el área de cobertura con una terminología que dé cuenta de la definición y tipología actuales para este tipo de perjuicios, para incluir o excluir ciertas cargas, y controlar de este modo el riesgo económico al que se ven abocados los servicios de gestión de siniestros.

\subsubsection{Acuerdos entre aseguradores del mercado colombiano y los perjuicios corporales}

Como se mencionó más arriba, los acuerdos entre aseguradores son un método eficaz para lograr una indemnización oportuna de las víctimas, así como para garantizar los recobros entre las entidades intervinientes. Sin embargo, hasta el momento, en Colombia solo existe un acuerdo de este tipo en materia de responsabilidad civil.

Se trata del denominado el Sistema Integrado de Gestión y Administración de Recobros (SIGAR), por medio del cual se organiza el flujo financiero entre aseguradoras por daños materiales en el Ramo Vehículos. Creado como una plataforma por la Federación de Aseguradores de Colombia (FASECOLDA) en el año 2010, este Sistema ha traído a las compañías aseguradoras diversos beneficios, como la disminución de costos, la agilización de transacciones y la organización de una operación masiva. El SIGAR contempla, entre otras cosas, un extenso manual para la determinación automática de la responsabilidad en choques entre vehículos ${ }^{117}$, en el cual se consignan diversidad de hipótesis para distribuir la responsabilidad entre cada uno de los vehículos implicados, ya sea de manera individual o compartida.

Sin embargo, al analizarse la posibilidad de establecer un sistema en el plano de la responsabilidad civil por daños a las personas, es menester reflexionar sobre las condiciones ideales para su instauración y dinámico funcionamiento. Una primera necesidad es disponer de reglas que permitan a las víctimas conocer de manera transparente y cierta, el valor de las indemnizaciones a las que tendría derecho. Si bien esto no

\footnotetext{
116 Corte Constitucional, sentencias T-152 de 2006, T-902 de 2013 y T-027-19.

117 Este manual se puede consultar en la página web https://www.sigarenlinea.com/sigar/ManualMARCUS.pdf.
} 
garantiza la ausencia de controversias frente al quantum, sin duda daría dinamismo a un sistema que pretenda un reconocimiento expedito y equitativo a las víctimas.

Por otro lado, sin desconocer las diferencias naturales y lógicas que habrán de presentarse en los seguros de responsabilidad civil ofertados en el mercado (v.gr. deducibles, límites asegurados, exclusiones, etc.), es imperativo contar con un lenguaje común, por lo menos desde un punto de vista conceptual. Ello en garantía de las víctimas, a fin de que no encuentren obstáculos en el sistema por discusiones que se puedan dar entre aseguradoras en un plano teórico.

\section{CONCLUSIONES: LA REPARACIÓN DE PERJUICIOS CORPORALES, MIRADAS COMPARATIVAS ENTRE COLOMBIA Y FRANCIA}

El concepto de daño corporal en Colombia se sujeta, en gran medida, al desarrollo jurisprudencial que ha tenido la denominada afectación psicofísica, siendo reconocida como fuente de perjuicios de diverso orden y que son objeto de protección por el ordenamiento jurídico. Sin embargo, es evidente que el daño corporal no goza del mismo protagonismo que tiene en otras latitudes, como Francia, país en el cual se creó una nomenclatura que abarca numerosas tipologías propias a los daños corporales, entre las cuales se pueden identificar algunas nociones que han escapado al debate y reconocimiento por parte de los jueces y del legislador colombianos.

Al enfoque existente de daño corporal como lesión psicofísica, se suma la ausencia de amplios debates en torno a este concepto, el cual, a pesar de ser de constante usanza en la actividad aseguradora y de ocasional mención por parte de los jueces colombianos en litigios de responsabilidad civil, no ha sido sometido a discusiones profundas sobre su contenido y delimitación. En este escenario resultan enriquecedoras las referencias que se pueden tomar del derecho francés, del cual somos plenos herederos ${ }^{118}$. Particularmente los debates jurídicos franceses en materia de responsabilidad civil, especialmente en lo que atañe a la cuantificación de perjuicios y a la constitución de acuerdos entre aseguradoras, son extrapolables a nuestro país como un ejemplo del derecho comparado en los países de origen europeo civilista en los cuales uno de los objetivos principales del sistema jurídico es alcanzar la reparación integral y expedita de víctimas.

Contrario a lo que afirman algunos ${ }^{119}$, puede afirmarse que en Colombia existe un sistema binormativo de reparación de perjuicios extrapatrimoniales ${ }^{120}$ por vía juris-

\footnotetext{
118 J.C. Henao (2015). Las formas de reparación en la responsabilidad del Estado: hacia su unificación sustancial en todas las acciones contra el Estado. Revista de Derecho Privado, (28), 277-366.

119 Un autor afirma que, con la adopción de las tablas de indemnización por el Consejo de Estado en 2014, el «gran derrotado es el sistema francés, en la medida en que la metodología no atomiza el perjuicio extrapatrimonial en múltiples categorías»: RoJAS QuiÑONES, S. (2014) ¿Cómo se debe cuantificar el daño según el Consejo de Estado y la Corte Suprema? (Parte I), Periódico Ámbito Jurídico, 7 de noviembre del 2014.

120 Siguiendo la distinción de estos sistemas dada en: L. C. SÁnchez Hernández (2012). Reflexiones en torno a las funciones de la condena por daños extrapatrimoniales a la persona a partir del estudio de la "iniuria” del derecho romano clásico. Revista de Derecho Privado, Núm. 23 (2012): julio-diciembre.
} 
prudencial, aunado al hecho de que en el ámbito internacional hay una tendencia a la diversificación de criterios y tipologías de indemnización ${ }^{121}$. En cualquier caso, consideramos que es irrelevante que todas las categorías se incluyan en una sola nomenclatura, o que se cree una nomenclatura para cada perjuicio independiente, puesto que lo que debe interesar en el debate público es que, probado el perjuicio, la reparación sea realizada. En efecto, identificar un monto específico por cada perjuicio corresponde en mejor medida al objetivo de protección de las víctimas, independientemente de si dicha suma puede o no ser exactamente cuantificada, pues éste es un tema más adjetivo que sustancial. No reparar un perjuicio so pretexto del riesgo de indemnizar más allá del daño ${ }^{122}$ es renunciar al objetivo propio de la responsabilidad civil y al rol de la rama judicial en la regulación de las relaciones sociales. Al respecto, debemos mencionar que el método de globalización de la reparación surge de la dificultad para determinar cuál era la amplitud de un determinado perjuicio frente a otro ${ }^{123}$. Este no es el caso hoy día, gracias al avance tecnológico que permite determinar con gran exactitud la afectación a la integridad física, así como el poder comparar un gran número de decisiones judiciales y encontrar un precedente adecuado para cada caso.

Francia es un sobresaliente ejemplo de que una discusión social alrededor del tema de la indemnización de perjuicios permite una retribución jurídica adecuada por el derecho de la responsabilidad civil frente a una realidad que presenta cada vez más siniestros en masa. Diversificar los criterios de indemnización es entonces reconocer que la persona humana tiene diferentes facetas las cuales deben ser todas objeto de reparación.

La introducción de una reparación daño-por-daño, o lo que algunos denominan el principio de vertebración ${ }^{124}$, deviene pues imperiosa. Si bien ciertas iniciativas legislativas van en este sentido, con la adopción de la reglamentación de la actividad del avaluador en seguros ${ }^{125}$ y la consagración de sanciones procesales en el área probatoria $^{126}$, nuestro país necesita que se conceptualicen los perjuicios que actualmente son reconocidos, identificando con claridad cuáles circunstancias corresponden a las categorías principales reconocidas por las Cortes, y a las subcategorías existentes. Este objetivo, que ha sido parcialmente cumplido en la jurisdicción administrativa con las

\footnotetext{
121 Ramírez, A. S. (2018). El daño a la persona en la experiencia comparada. Revista Aequitas, Número, 37-52.

122 Sobre este tema, un autor afirma: «el concepto de reparación integral es imposible de delimitar en materia de perjuicios extrapatrimoniales. El Consejo de Estado, cada día con más vehemencia, otorga cifras astronómicas por este concepto, como si la reparación integral no tuviera límites» J. Tamayo Jaramillo (2015) El desborde de las condenas contra el Estado, Periódico Ámbito Jurídico, 28 de marzo del 2016.

123 A. S. Epstein (2010). Présentation de la nomenclature des préjudices réparables en cas d'atteintes à l'environnement, Revue Vertigo, la revue électronique en sciences de l'environnement, Hors-série 8 octobre 2010.

124 Pantoja Bravo, J. (2015). El principio de vertebración en el "daño a la salud” en Colombia, Periódico Ámbito Jurídico, 7 de julio del 2015.

125 Mediante la Ley $N^{\circ} 1673$ de 2013 se reglamentó la actividad del avaluador, reglamentada por el Decreto 556 de 2014.

126 El art. 206 del Código de Procedimiento Civil exige la discriminación de los conceptos frente a los cuales se pide indemnización, así como el art. 227 del mismo Código que prevé el termino perentorio para aportar el dictamen pericial por las partes. Por otro lado, el art. 16 de la Ley N ${ }^{\circ} 446$ de 1998 exigía la observancia de criterios técnicos actuariales en la valoración de daños irrogados a las personas.
} 
sentencias gemelas de 2014, permitirá limitar la litigiosidad innecesaria y la congestión de la justicia, además de hacer más efectivas y oportunas las indemnizaciones, reduciendo los costos de la gestión de siniestros.

En Colombia, no existe un baremo instituido mediante ley o decreto, de forma que aún impera el arbitrium judicis, el cual se identifica en su más pura manifestación en la jurisdicción ordinaria, la cual no goza de tablas ni de guía alguna para la determinación del quantum indemnizatorio, más allá de ciertos topes jurisprudenciales dispuestos en las providencias de las Altas Cortes.

Es particularmente preocupante que algunos profesionales del derecho presenten reclamaciones de cuantías muy altas a pesar de que la Jurisprudencia de Cierre a claramente limitado el resarcimiento a ciertos montos. Al respecto, es lamentable que las iniciativas que buscaban sancionar las pretensiones exageradas en el juramento estimatorio de perjuicios no hayan tenido la efectividad que habría querido el legislador ${ }^{127}$, además de que las disposiciones del Código de Ética de los Abogados que se relacionan con este tema no sean objeto de sanción por la jurisdicción disciplinaria ${ }^{128}$. La extrapolación de las tablas de la Sección Tercera a escenarios civiles se puede apreciar como un clamor por la adopción de reglas de cuantificación, aunque ello puede obedecer a otras razones, especialmente la superioridad en las cifras indemnizatorias contempladas por la jurisdicción contencioso-administrativa para perjuicios inmateriales.

En Francia, a falta de una disposición legislativa instituyendo un baremo, las Cortes de Apelación, expidieron un referencial de indemnización cuyo fundamento son los montos efectivamente otorgados en precedentes jurisprudenciales compendiados ${ }^{129}$. Estas iniciativas de orden judicial, avistada en ambos países, no pueden sino ser beneficiosas puesto que, más allá de establecer sanciones, buscan racionalizar las controversias, crear reglas claras y mejorar la seguridad jurídica.

Ahora, si bien es cierto que el hecho de que no sean documentos vinculantes, o por lo menos adoptados por un órgano legislativo, puede restarles efectividad a estos referentes, lo que hay que señalar es que debe ser una actividad esencial del abogado y de la doctrina, el hacerle ver a los jueces que una nomenclatura construida a través de esfuerzos colectivos para compendiar la jurisprudencia es fuente de derecho aplicable. Colombia y Francia son integrantes de la comunidad del Civil Law ${ }^{130}$, en la cual la regla jurisprudencial es directamente aplicable, al mismo título que la ley. La tarea entonces es encontrar la jurisprudencia que se acopla especialmente al caso, siguiendo las reglas

\footnotetext{
127 Vale la pena anotar que en Colombia el juramento estimatorio, consagrado en el art. 206 del Código General del Proceso, no tiene aplicación en la cuantificación de perjuicios extrapatrimoniales, siendo esta tipología la que enmarca aquellos perjuicios frente a los cuales se advierte continuamente el planteamiento de pretensiones ostensiblemente superiores a los montos reconocidos por la jurisprudencia para casos similares.

${ }^{128}$ Los numerales 13, 16 y 18 literal a) de la Ley $\mathrm{N}^{\circ} 1123$ de 2007 deberían ser aplicados respecto de las pretensiones manifiestamente exageradas.

129 Référentiel indicatif de l'indemnisation du préjudice corporel des cours d'appel, Conférence des premiers présidents de cours d'appel de France, Septembre 2016.

130 Siguiendo la noción contemporánea del derecho civil continental utilizada en los ordenamientos que fueron objeto de procesos de constitucionalización.
} 
propias del derecho judicial, afincado en el aforismo stare decisis ${ }^{131}$, que hace del precedente jurisprudencial, particularmente el de casación, ley directamente aplicable ${ }^{132}$.

Consideramos que, tratándose de documentos de origen judicial, que reflejan las discusiones académicas y sociales alrededor del tema de la indemnización de perjuicios corporales, la modificación y actualización de los mismos puede evitar toda animosidad regresionista del gobierno o parlamento de turno, pues es la jurisprudencia la que se encarga, caso a caso, de hacer evolucionar el baremo pretoriano así construido. En efecto, es necesario que la nomenclatura tenga la flexibilidad necesaria para delimitar algunos perjuicios o incluso para incluir nuevos, a medida que los cambios sociales se van sucediendo. Este ha sido el caso respecto de los ataques terroristas, que en Francia motivaron la inclusión de tres nuevos tipos de daño que no estaban inicialmente concebidos en la nomenclatura Dintilhac ${ }^{133}$ y que en Colombia se autorizara a los jueces reajustar las condenas cuando las personas fueron víctimas de actos terroristas de gran ferocidad y barbarie ${ }^{134}$. Esta prerrogativa respecto de los perjuicios corporales se debe ejercer con sensatez, para no exceder las condenas razonables y pagar la integralidad del perjuicio, prudencia que en Colombia puede esperarse más de los jueces que del legislador ${ }^{135}$.

\section{BIBLIOGRAFÍA}

M. Le Roy et al. (2018). L'évaluation du préjudice corporel. Ed: LexiNexis.

P. CASSON. Règles propres au dommage corporel, Dommages et intérêts: Évaluation judiciaire des dommages et intérêts, Jurisclasseur LexisNexis, Février 2017 (2019), recuperado: 13.10.2019.

M. Delmas-Marty (2019). Sortir du pot au noir: l'humanisme juridique comme boussole, Paris: Buchet Chastel.

L. C. SÁnChez HeRnández (2012) Reflexiones en torno a las funciones de la condena por danos extrapatrimoniales a la persona a partir del estudio de la "iniuria" del derecho romano clásico, Revista de Derecho Privado, Núm. 23 (2012): julio-diciembre.

\footnotetext{
131 Una exposición sucinta de este método, en español: LóPEz Medina, Diego Eduardo. El derecho de los jueces, Legis, Universidad de los Andes, Bogotá, 2004, y en francés: M. Amilhat (2014). L'existence méconnue d'une règle du précédent en droit administratiffrançais - Réflexions sur les mécanismes de création $d u$ droit par le juge, Lextenso, Petites afiches, n¹6 p. 4, 22/01/2014.

132 La Corte Constitucional en Sentencia C-836 de 2001 habla de «fuerza normativa de la doctrina dictada por la Corte Suprema». Esta sentencia de constitucionalidad es uno de los fundamentos citados en el obiter dicta por la Corte Suprema de Justicia en Sentencia de 19 de diciembre de 2018, SC5686-2018 0573631 89001200400042 01, M.P. Margarita Cabello Blanco.

133 Cfr. Op. Cit. A. Coignac (2018).

134 Se trato de las consecuencias de un ataque del ELN en un oleoducto en la población rural: Corte Suprema de Justicia, Sentencia de 19 de diciembre de 2018, SC5686-201805736 3189001200400042 01, M.P. Margarita Cabello Blanco.

135 Un ejemplo de ello es la Sentencia mencionada de 19 de diciembre de 2018 de la Corte Suprema de Justicia que, aunque aumentó los valores del daño a la vida de relación, no reconoció un daño a los intereses constitucionales propiamente dichos.
} 
Y. Lambert-Faivre et S. Porchy-Simon (2015). Droit du dommage corporel. Systèmes d'indemnisation, Ed: Précis Dalloz, $\mathrm{n}^{\circ} 16$.

A. LAUDE et al. $(2015,2019)$ Existence d'un droit fondamental à la réparation du dommage corporel? ํ557-30, Le Lamy Droit de la santé, LamyLine, Wolters Kluwer.

Solarte Rodríguez, A. (2017). El principio favor victimae y su aplicación en el derecho colombiano, Anuario de Derecho Privado, 2017 Facultad de Derecho, pp. 257-304.

Cour de cassation, deuxième chambre, 18 avr. 1969, no 67-14.072, Bull. civ. II, no 82.

TAYLOR, Simon. "L'indemnisation du risque thérapeutique en droit anglais et la possibilité d'un rapprochement des systèmes européens". In: Revue internationale de droit comparé. Vol. 57 N³, 2005., pp. 717-732.

Lalinde S. et al. (2010) Encuesta Nacional de Necesidades jurídicas, Dejusticia, Análisis general y comparativo para tres poblaciones.

P. BRUn, et al. (2019) Dommage corporel: données de base théoriques et pratiques, n²24, Le Lamy Droit de la responsabilité, Wolters Kluwer.

T. PAPART (2013) Regards croisés sur l'indemnisation du préjudice corporel en France et en Belgique, Revue Le Lamy Droit civil, № 106, Wolters Kluwer.

Rapport Busnelli F Académie de droit européen de Trèves, Congrès 8 et 9 juin 2000, citado en Op. Cit. T. Papart (2013).

S. Porchy-Simon, et al. (2015). Dommage corporel, Recueil Dalloz 2015, p. 2283.

C. BLoch (2018-2019). Domaine de l'indemnisation des victimes contaminées par le sida ou l'hépatite C à la suite d'une transfusion sanguine, Droit de la responsabilité et des contrats, Dalloz Action, Chapitre 6431.

P. Le Tourneau (209) Droit des dommages corporels, Responsabilité: généralités, Dalloz Répertoire de droit civil.

B. Edelman (2002). L'arrêt «Perruche»: une liberté pour la mort?, Recueil Dalloz pág.2349

J. LANDel (2019) Dommages corporels, Dictionnaire Permanent Assurances, Editions Législatives, ELNet.

P.L. Bras et al. (2007). Rapport de l'assurance de responsabilité médicale, Collège français d'échographie foetale.

J. Penneau (2013, 2019). Préjudice, Répertoire de droit civil / Médecine: réparation des conséquences des risques sanitaires, Répertoire de droit civil 2013, Dalloz.

F. Limoge (2010). Des règles communes de gestion des dommages corporels, Argus de l'assurance, 2010, recuperado: https://www.argusdelassurance.com/le-point-sur/des-regles-communes-de-gestion-des-dommages-corporels.50808

La CEDH condamne la rétroactivité de la loi française "anti-Perruche" (2008). Le Monde, recuperado 13.09.2019: https://www.lemonde.fr/societe/article/2005/10/06/la-cedh-condamne-la-retroactivite-de-la-loi-francaise-anti-perruche_696611_3224.html. 
Federación Francesa de Aseguradoras (2017) Les assurances en cas d'accidents corporels à adhésion individuelle, recuperado 13.09.2019 en: https://www.ffa-assurance.fr/etudes-et-chiffres-cles/les-assurances-en-cas-accidents-corporels-adhesion-individuelle-en-2017.

Y. LAMBERT-FAIVRE (2003). Rapport sur l'indemnisation du dommage corporel.

L’indemnisation du préjudice corporel (2017) Annuaire Juridique Pénal, Dalloz.

Référentiel indicatif de l'indemnisation du préjudice corporel des cours d'appel, Conférence des premiers présidents de cours d'appel de France, Septembre 2016.

Ecole nationale de la Magistrature (2016) Référentiel indicatif de l'indemnisation du préjudice corporel des cours d'appel.

Association pour l'étude de la Réparation du Dommage Corporel (2014) Mission droit commun d'expertises médicales.

H. Adida-CANAC (2011). Le contrôle de la nomenclature Dintilhac par la Cour de cassation, Recueil Dalloz p.1497.

N. Kilgus (2016). Préjudice esthétique temporaire et poste de préjudice du déficit fonctionnel temporaire, Répertoire Dalloz actualité, 22 février 2016 n 10-23.378.

Mission confiée au groupe de travail d'élaborer une nomenclature commune des préjudices corporels, Conseil des ministres, le 29 septembre 2004.

H. Pelosse et al. (2017) Revue des dépenses, Le recours contre tiers des caisses de sécurité sociale, Inspection générale des finances, $\mathrm{N}^{\circ} 2017-\mathrm{M}-004$.

J. Kullmann et al. (2019) Critère de qualification $n^{\circ} 18$, Partie 1 Le contrat d'assurance, Le Lamy Assurances, Wolters Kluwer.

A. Coignac (2018). L'évolution de la prise en charge des victimes d'actes de terrorismo, Dalloz Actualité, 5 mars 2018.

G. FernÁNDEZ CRUZ (2015). La dimensión omnicomprensiva del daño no patrimonial y la reclasificación de los daños, Revista Advocatus n³1, Asociación Civil ADV Editores, Lima.

A. M. NAVARREte-Frías (2009) La responsabilidad del Estado y su adecuación a parámetros interamericanos, Estud. Socio-Juríd., Bogotá (Colombia), 11(2): 335-376, julio-diciembre de 2009.

J. I. MANRiQue NiÑo (2007). La reparación del daño antijurídico en la prestación del servicio público de la educación, Estud. Socio-Juríd., Bogotá (Colombia), 9(1): 205-246, enero-junio de 2007.

J.C. Henao (2015). Las formas de reparación en la responsabilidad del Estado: hacia su unificación sustancial en todas las acciones contra el Estado. Revista de Derecho Privado, (28), 277-366.

M. Foucault (1973). La vérité et les formes juridiques, Dits Ecrits tome II texte n¹39.

López Medina, Diego Eduardo. El derecho de los jueces, Legis, Universidad de los Andes, Bogotá, 2004, p. 140. 
C.F. SessaRego (1998). Daño a la persona y daño moral en la doctrina y en la jurisprudencia latinoamericana actual, THĒMIS-Revista de Derecho, $\mathrm{n}^{\circ}$ 38, 1998, Pontificia Universidad Católica del Perú.

Hinestrosa, F. (2017). Devenir del derecho de daños. Revista de Derecho Privado, (32), 5-26.

E. Gil Botero (2012). El daño a la salud en Colombia-retos frente a su delimitación, valoración y resarcimiento. Revista Digital de Derecho Administrativo. 8 (dic. 2012), 89-145.

Henao, J.C. (1998) El Daño (segunda reimpresión: abril de 2007). Colombia: Universidad Externado de Colombia.

J. TAmayo Jaramillo, et al. (2017). Nuevas reflexiones sobre el daño. Colombia. Legis.

J. TAmayo Jaramillo (2015). El desborde de las condenas contra el Estado, Periódico Ámbito Jurídico, 28 de marzo del 2016.

S. RoJas QuiÑones. ¿Hacia una “nueva” responsabilidad civil?, Periódico Ámbito Jurídico, 23 de febrero del 2017

S. RoJAS QuiÑones ¿Cómo se debe cuantificar el daño según el Consejo de Estado y la Corte Suprema? (Parte I), Periódico Ámbito Jurídico 07 de noviembre del 2014.

M. A. Aramburo (2018) ¿Villaveces o Rosazza? Una hipótesis sobre el daño moral, Periódico Ámbito Jurídico, 6 de Julio del 2018, Bogotá.

E. CoRTÉs (2009). Responsabilidad civil y daños a la persona, Ed. Universidad Externado de Colombia.

D. A. SANDOVAL GaRrido (2013). Reparación integral y responsabilidad civil: el concepto de reparación integral y su vigencia en los daños extrapatrimoniales a la persona como garantía de los derechos de las víctimas. Revista de Derecho Privado, Universidad Externado n`25 (dic. 2013), 237-273.

JARAmillo Sierra, C., and P. N. Robles BACCA. La reparación del daño extrapatrimonial a la persona por incumplimiento contractual: la experiencia colombiana. Revista de Derecho Privado [1998], 2014, p. 499.

Manual del Sistema Integrado de Gestión y Administración de Recobros (SIGAR).

Ramírez, A. S. (2018). El daño a la persona en la experiencia comparada. Revista Aequitas, Número, 37-52.

A. S. EPSTEIN (2010). Présentation de la nomenclature des préjudices réparables en cas d'atteintes à l'environnement, Revue Vertigo, la revue électronique en sciences de l'environnement, Hors-série 8 | octobre 2010.

Pantoja Bravo, J. (2015). El principio de vertebración en el "daño a la salud" en Colombia, Periódico Ámbito Jurídico, 7 de Julio del 2015.

M. Амilнat (2014). L'existence méconnue d'une règle du précédent en droit administratif français-Réflexions sur les mécanismes de création du droit par le juge, Lextenso, Petites afiches, $n^{\circ} 16$ page $4,22 / 01 / 2014$.

Allianz Seguros S.A., Seguro de Responsabilidad Civil Extracontractual General (Condicionado 24/11/2016-1301-P-06-Rce100 V3).

Aseguradora Solidaria de Colombia Entidad Cooperativa. Seguro de Responsabilidad Civil Extracontractual (condicionado 16/03/2018-1502-P-06-GENER-CL-SUSG-04-DROI 
SBS Seguros Colombia S.A., Seguro de Responsabilidad Civil Extracontractual (Condicionado 21032018-1322-P-06-RESP_CIVILEXTRAC-D00I).

Axa Colpatria Seguros S.A. Seguro de Incendio - Alianzas Pyme Protegida (Condicionado 28/07/2017-1306-Nt-P-07-P/0831julio/2017).

Liberty Seguros S.A. Seguro de Responsabilidad Civil Extracontractual General (Condicionado 26/11/2016-1333-P-06-Rc-02).

La Previsora S.A. Compañía de Seguros. Seguro De Responsabilidad Civil Extracontractual (condicionado 30/12/2013-1324-P-06-Rcp016v4).

La Equidad Seguros Generales Organismo Cooperativo, Seguro de Responsabilidad Civil Extracontractual (Condicionado 15062010-1501-P-06-0000000000001001).

Seguros del Estado S.A., Seguro de Responsabilidad Civil Extracontractual (Condicionado 26/11/2016-1329-P-06-Erce003a).

La Previsora S.A. Compañía de Seguros, Seguro de Responsabilidad Civil Extracontractual (condicionado 01/08/98-1324-P-00-Pyme002).

Seguros Generales Suramericana S.A., Seguro de Responsabilidad Civil por Daños a Terceros (Condicionado F-01-13-066).

\section{Sentencias de Colombia}

Corte Constitucional, Sentencia C-916 de 2002.

Corte Constitucional en Sentencia C-836 de 2001

Corte Constitucional, Sentencia C-753 de 2013.

Corte Constitucional, Sentencia T-152 de 2006.

Corte Constitucional, Sentencia T-902 de 2013.

Corte Constitucional, Sentencia T-027-19.

Corte Suprema de Justicia, Sentencia de 4 de abril de 1968, cit., G.J. CXXIV, 63,

Corte Suprema de Justicia, Sala Civil sentencia de 25 de noviembre de 1992, exp. 3382.

Corte Suprema de Justicia, Sala Civil sentencia de 6 de mayo de 2016, n SC5885-2016.

Corte Suprema de Justicia, Sala Penal, Sentencia de 30 de agosto de 2017, SP134512017 (48231).

Corte Suprema de Justicia, Sentencia del 01 de 13 de mayo de 2008 (exp. $1100131030061997-$ 09327-), p. 57.

Corte Suprema de Justicia, Sentencia No. 11001-31-03-003-2003-00660-01 de 5 de agosto de 2014.

Corte Suprema de Justicia, Sala de Casación Civil, Sentencia de 13 de mayo de 2008, Exp. 11001-3103-006-1997-09327-01.

Corte Suprema de Justicia, Sala Civil, Sentencia de 19 de diciembre de 2017, SC-220362017 (73001310300220090011401). 
Corte Suprema de Justicia, Sentencia de 19 de diciembre de 2018, SC5686-2018 057363189 001200400042 01, M.P. Margarita Cabello Blanco.

Corte Suprema de Justicia, Sala Civil, Sentencia de 12 de diciembre de 2017 nº SC-209502017 (05001310300520080049701).

Consejo de Estado, Sentencia de 14 de septiembre de 2011, radicación nro. 05001-23-25-0001994-00020-01, nro. Interno 19031.

Consejo de Estado, Sección Tercera, sentencia de unificación jurisprudencial del 28 de agosto de 2014, Exp. 32988, M.P. Ramiro Pazos Guerrero

Consejo de Estado, Sentencia de 28 de agosto de 2014, exp. 50001231500019990032601 (31172), C.P. Olga Mélida Valle de la Oz.

Consejo de Estado, Sentencia de 18 de mayo de 2017, nº5001-23-31-000-1998-04063-01 Sala de lo Contencioso Administrativo, Sección Tercera.

Consejo de Estado, Sección Tercera, 19 de septiembre de 2019, C.P. Marta Nubia Velásquez Rico, Rad. 52898.

Consejo de Estado, Sentencia de 30 de septiembre del 2016 SC13925-2016, no 05001-31-03003-2005-00174-01, M.P. Ariel Salazar Ramírez.

Consejo de Estado, Sección Segunda, Sentencia 11001031500020180073700 , May. 3/18, CP. Gabriel Valbuena Hernández.

Consejo de Estado, Sentencia de 14 de septiembre de 2011, Sección Tercera $n^{\circ}$ 05001-23-31000-2007-00139-01(38222), C.P.: Enrique Gil Botero.

Consejo de Estado, Sección Tercera en sentencia del 1 de julio de 1993, exp. 7772.

Consejo de Estado, Sentencia de 30 de septiembre del 2016, SC13925-2016, nº 05001-31-03003-2005-00174-01, M.P. Ariel Salazar Ramírez. 